University of Louisville ThinkIR: The University of Louisville's Institutional Repository

Electronic Theses and Dissertations

$5-2016$

\title{
Positive deviance, contraceptive self-efficacy and social desirability in sexually active adolescent females : a mixed methods approach.
}

Ashley D. Miller

University of Louisville

Follow this and additional works at: https://ir.library.louisville.edu/etd

Part of the Obstetrics and Gynecology Commons, Other Nursing Commons, and the Public Health and Community Nursing Commons

\section{Recommended Citation}

Miller, Ashley D., "Positive deviance, contraceptive self-efficacy and social desirability in sexually active adolescent females : a mixed methods approach." (2016). Electronic Theses and Dissertations. Paper 2398.

https://doi.org/10.18297/etd/2398

This Doctoral Dissertation is brought to you for free and open access by ThinkIR: The University of Louisville's Institutional Repository. It has been accepted for inclusion in Electronic Theses and Dissertations by an authorized administrator of ThinkIR: The University of Louisville's Institutional Repository. This title appears here courtesy of the author, who has retained all other copyrights. For more information, please contact thinkir@louisville.edu. 
POSITIVE DEVIANCE, CONTRACEPTIVE SELF-EFFICACY AND SOCIAL DESIRABILITY IN SEXUALLY ACTIVE ADOLESCENT FEMALES: A MIXED

\author{
METHODS APPROACH
}

\author{
By \\ Ashley D. Miller \\ B.S.N., Berea College, 2005 \\ M.S.N., University of Louisville, 2008
}

\begin{abstract}
A Dissertation
Submitted to the Faculty of the School of Nursing of the University of Louisville in Partial Fulfillment of the Requirements for the Degree of
\end{abstract}

Doctor of Philosophy in Nursing

Department of Nursing

University of Louisville

Louisville, Kentucky

May 2016 
Copyright 2016 by Ashley D. Miller

All rights reserved 

POSITIVE DEVIANCE, CONTRACEPTIVE SELF-EFFICACY AND SOCIAL DESIRABILITY IN SEXUALLY ACTIVE ADOLESCENT FEMALES: A MIXED METHODS APPROACH

By

Ashley D. Miller

B.S.N., Berea College, 2005

M.S.N., University of Louisville, 2008

A Dissertation Approved on

April 7, 2016

by the following Dissertation Committee

\begin{tabular}{c}
\hline Dissertation Director \\
Marianne H. Hutti, PhD, WHNP-BC \\
\hline Tim Crawford, PhD, MPH \\
\hline Vicki Hines-Martin, PhD, CNS, RN, FAAN \\
\hline Cynthia Logsdon, PhD, WHNP-BC, FAAN \\
Nancy M. Theriot, PhD
\end{tabular}




\section{DEDICATION}

I dedicate this dissertation to my grandmother, Patricia Ann Brady and my grandfather, Joseph Jesse Brady. I thank you sincerely for your willingness to create peace for me in a world of chaos. Thank you for always being there, for always believing in me, for always supporting my dreams. Your sacrifice will never be forgotten. 


\section{ACKNOWLEDGEMENTS}

This dissertation has been a tremendous journey. A journey that began over five years ago with the idea that someone needed to do research to help me understand why my adolescent female patients who said they did not want to get pregnant weren't using birth control consistently if at all. That someone became me, and although this dissertation bears my name, it took a village to successfully get me to this place.

First, I would like to express my sincerest gratitude to my Dissertation Chairperson, Dr. Marianne Hutti for the countless hours she committed to supporting me along the entire PhD journey. Her expert guidance, tactful challenges coupled with refreshing encouragement were instrumental and greatly appreciated. Dr. Hutti is a great example of a scholar, teacher and a studentadvocate. I am grateful to have had the opportunity to work with and learn from her.

Additionally, I was blessed to have an All-Star dissertation committee.

Drs. Tim Crawford, Vicki Hines-Martin, Cindi Logsdon, and Nancy Theriot, I thank you all for providing me with constant encouragement and great insight. Thank you for your endless feedback on my project and for constantly pushing me to think outside the box. You each have contributed significantly to my growth as both a scholar and as a woman. 
Next, I would like to thank my entire family who have been there every step of the way along this journey and I feel honored to share this work with them. To my mother, Michele, thank you for daily encouragement, words of wisdom and prayer. Even when I couldn't picture the end myself, she painted the picture for me, allowed me to vent and cry, but always ended each conversation with "you can do it!" To my father, Keith Sr. thank you for constantly being the pillar of hope, that if you put your mind to anything, you can achieve it. To my brother, Keith Jr. this one's for you! I've set out on many an escapade with him in my heart. l've always wanted to be a great role model for him and achieve my goals so that one day, he could use my path as motivation to go after his goals with great tenacity! Miss Denise, you've taken such good care of me over the years. Your constant support and encouragement means the world to me, and I would not be the woman I am without you.

Lastly, but certainly not least, I want to thank my beloved, Derek L. Anderson, Sr. who encouraged me daily and proofread countless drafts of manuscripts, listened to me vent and supported me through the day to day grind of completing this dissertation. His unwavering commitment to help me through this degree both financially and emotionally has been beyond amazing. I could not have done it without him. Thank you, from the deepest place in my heart, and I look forward to the next chapter of our lives together. 


\section{ABSTRACT \\ POSITIVE DEVIANCE, CONTRACEPTIVE SELF-EFFICACY AND SOCIAL DESIRABILITY IN SEXUALLY ACTIVE ADOLESCENT FEMALES: A MIXED METHODS APPROACH}

Ashley D. Miller

April 7, 2016

Unintended pregnancy is an issue that impacts women of all ages, ethnicities, and socioeconomic statuses. It also impacts the child that results and the society in which they live. In the United States, adolescents experience unintended pregnancy more than adolescents in other countries.

The purpose of this dissertation was to explore the factors that contribute to successful contraceptive use among adolescent females (ages 13-18) seeking reproductive health services at a local family planning clinic. The theoretical framework of contraceptive self-efficacy (CSE) was used to frame this understanding. The exploration was conducted in three ways: a critical review of the literature on contraceptive self-efficacy; an examination of contraceptive selfefficacy in adolescent females seeking reproductive health care services at a local family planning clinic; and a qualitative exploration of adolescent girls who 
had consistently used birth control for at least one year without the experience of an unintended pregnancy (positive deviants).

The critical review of the literature demonstrated that additional research on CSE as a predictor of contraceptive use has the potential to improve contraceptive use among adolescent girls. The Contraceptive Self-Efficacy Scale (CSS) has not been used comprehensively in the past, and further research using the CSS is needed to explore the variance in contraceptive use left unexplained. In the next manuscript, the CSE of adolescent females seeking reproductive health services at a local family planning clinic was evaluated along with the psychometric properties of the CSS. This study showed that CSE is impacted by demographic and medical variables, and is minimally influenced by social desirability. Factor analysis of the CSS suggested additional research is needed to explore the appropriateness of using a shortened version of the CSS. In the final manuscript, the characteristics of positive deviants seeking reproductive health care at a local family planning clinic were examined to determine how they navigate external influences to become successful contraceptive users. Study results revealed that positive deviants have consistent characteristics that assist them in being successful contraceptive users. These characteristics need further exploration.

The findings of this dissertation support previous research that has identified the importance of CSE as a variable influencing birth control use. Contraceptive self-efficacy is influenced by demographic and medical variables and the use of the CSS is recommended for future studies of CSE. Additionally, 
positive deviants in the reproductive health realm have consistent characteristics that, if developed and taught to adolescent girls, may increase their contraceptive use. Interventions aimed at improving CSE among adolescent females and teaching characteristics such as assertiveness, responsibility, and career planning may improve contraceptive use, thus decreasing the unintended pregnancy rates among adolescent and adult females alike. 


\section{TABLE OF CONTENTS}

DEDICATION

PAGE

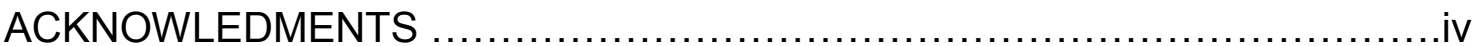

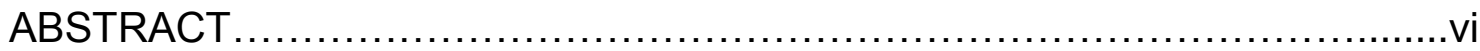

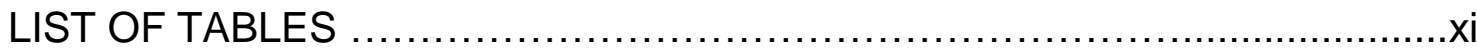

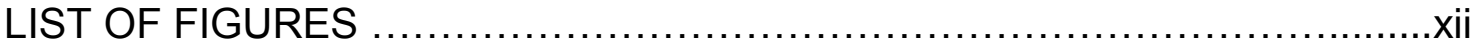

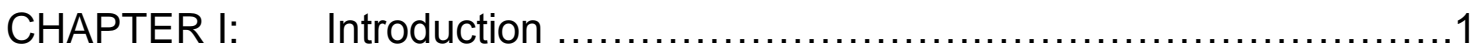

CHAPTER II: Contraceptive Self-Efficacy: A Critical Review of the Literature

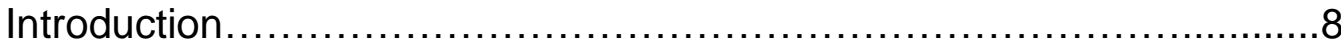

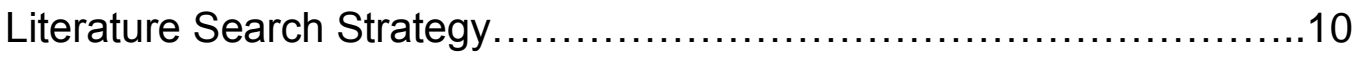

Results...........................................................................

Critique of the Literature.................................................

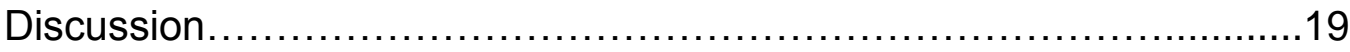

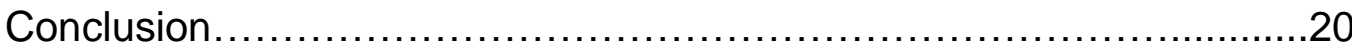

CHAPTER III: Urban Adolescent Females: Contraceptive Self-Efficacy and the Contraceptive Self-Efficacy Scale

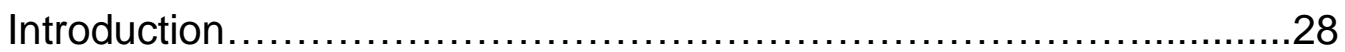

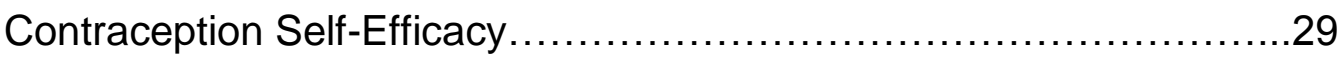

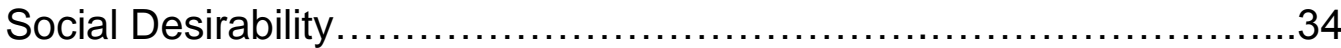

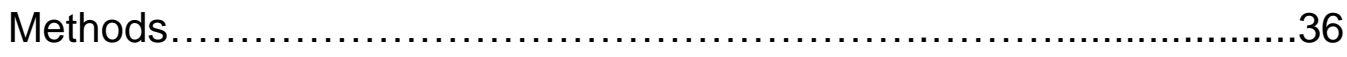

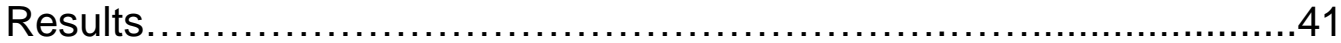


Discussion.

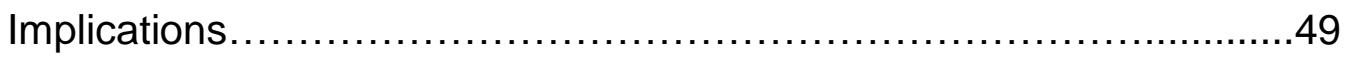

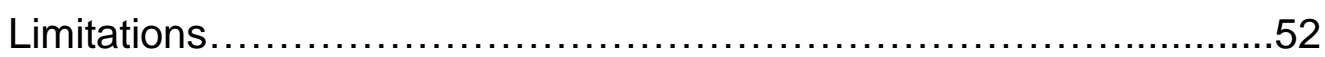

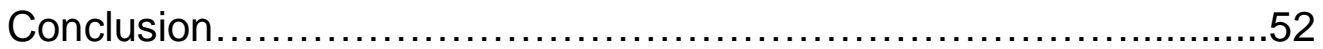

CHAPTER IV: Positive Deviants in Family Planning: A Qualitative Study

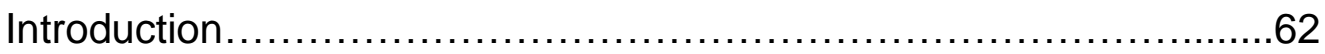

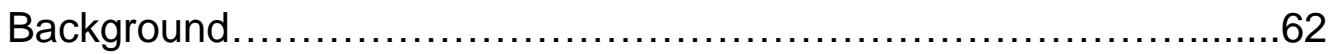

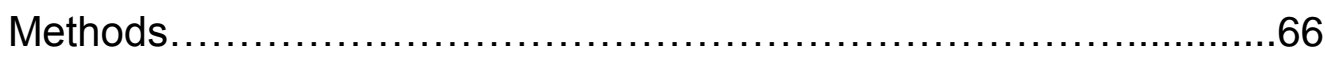

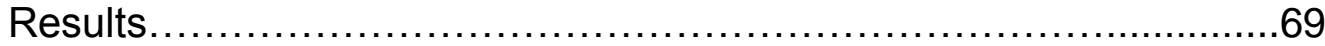

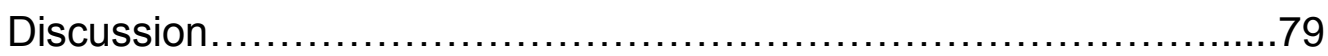

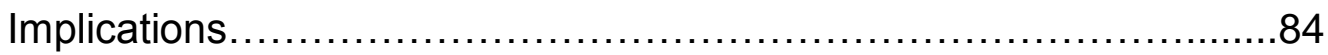

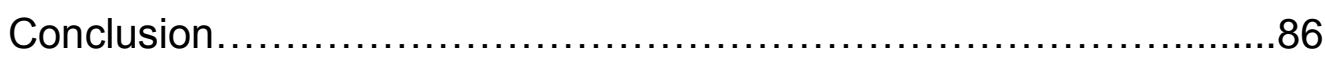

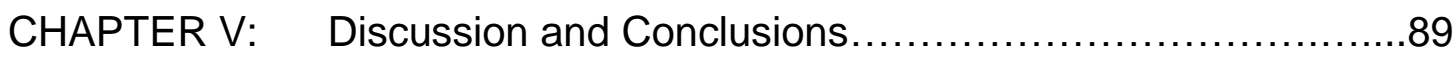

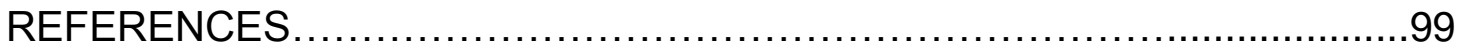

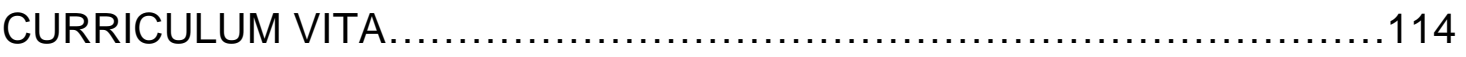




\section{LIST OF TABLES}

TABLE

PAGE

1. Studies of Contraceptive Self-Efficacy in Females from 1984-2015

2. Demographic Characteristics among 180 Adolescent Females Seeking

Reproductive Health Services at a Local Family Planning Clinic

3. Factor Analysis of the Contraceptive Self-Efficacy Scale: Comparing Current Study Results to Levinson's (1986) Results

4. Mean Contraceptive Self-Efficacy Scores of 180 Adolescent Females Seeking Reproductive Health Services at a Local Family Planning Clinic ....57

5. Study Variables Correlated to Contraceptive Self-Efficacy in Adolescent Females Seeking Reproductive Health Services at a Local Family Planning Clinic

6. Mean Differences in Contraceptive Self-Efficacy Scale Scores among Adolescent Females Seeking Reproductive Health Services at a Local Family Planning Clinic 60

7. Predictors of Contraceptive Self-Efficacy in Adolescent Females Seeking Reproductive Health Services at a Local Family Planning Clinic

8. Demographic Characteristics Among 10 Positive Deviants Seeking Reproductive Health Services at a Local Family Planning Clinic 


\section{LIST OF FIGURES}

FIGURE $\quad$ PAGE

1. Illustration of the contraceptive self-efficacy theoretical framework .........61

2. Model of positive deviant characteristics encouraging consistent

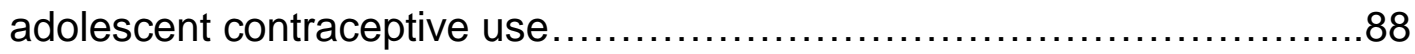




\section{CHAPTER 1}

\section{INTRODUCTION}

The primary purpose of this dissertation was to explore the factors that contribute to successful contraceptive use among adolescent females (ages 1318) seeking reproductive health services at a local family planning clinic. Factors influencing teen contraceptive use and unintended pregnancy are of great significance to adolescent health, women's health and nursing practice. Both quantitative and qualitative data are combined in this dissertation to provide context and greater understanding to complex social problem. This was accomplished by examining both the quantitative numeric trends with detailed qualitative insight.

In addition to this introductory chapter, the dissertation includes three manuscripts and a concluding chapter that summarizes and links the findings of the three manuscripts. First, a critical review of the literature on contraceptive self-efficacy (CSE) was completed to identify gaps in the literature as well as to identify the most comprehensive use of the Contraceptive Self-Efficacy Scale (CSS) for future research. Next, the psychometric properties of the CSS were evaluated along with factors that may influence CSE in the study population. Finally, characteristics of adolescent girls who were successful contraceptive users (positive deviants) were explored qualitatively to evaluate similarities and 
differences as well as how they navigate external influences to become successful contraceptive users.

\section{Background and Significance}

In the United States today, we are inundated with technology, medical advancements, and due to the Affordable Care Act, have much more access to contraception; however, the United States continues to have the highest rate of teenage pregnancy when compared to other developed nations (Nicoletti, 2004; Kearney \& Levine, 2012). Beyond this, teens in the United States are less likely than their counterparts in other countries to use available contraceptive methods (Nicoletti, 2004; Kearney \& Levine, 2012). Research suggests that an adult's health status and health behaviors are greatly influenced by patterns and behaviors developed during adolescence (USDHHS, 2012). Teen pregnancy, unintended pregnancy, and sexually transmitted infections have each been described as public health and social issues that begin during adolescence (USDHHS, 2012; ACLU, 2013). Although adolescent pregnancy is a personal issue, it is also one of great public concern; as such, health care providers have the responsibility to assist teens in decreasing sexual risks (Committee on Adolescence, 2007).

In the United States, a large percentage of high school students are sexually active. In 2012, it was found that nationally, $47.4 \%$ of high school students have had sex (CDC, 2012). The number of sexually active high school students increased from 2009-2012, but what is most alarming is that the percentage of sexually active students that reported using a condom during their 
last sexual encounter has steadily decreased since 2003 (from 63\%), and in 2012 was down to $60.2 \%$. In Kentucky, the statistics are even more alarming. In $2013,51.8 \%$ of high school students are sexually active, but only $49.4 \%$ reported using a condom during their last sexual encounter (CDC, 2015). This decline in contraception use, including condoms, is significant to the overall health of American teens, and especially teens in Kentucky, but has not been fully explored in research thus far.

\section{Unintended Pregnancy in the United States}

An unintended pregnancy is any pregnancy in which the mother reports it as mistimed or unwanted (USDHHS, 2012). During 2006, almost half of all pregnancies in the United States were unintended. In this same year, the prenatal care, labor and delivery, post-partum care and infant care from unintended pregnancies carried to term cost America $\$ 11$ billion (USDHHS, 2012). Today, $45 \%$ of pregnancies in the United States are unintended, a percentage higher than most other developed nations (Guttmacher, 2016). Unintentional pregnancy impacts all women. Although women who are between the ages of $18-24$, cohabiting with a male partner, earning an income below the federal poverty line, have less than high school education and are black or Hispanic have the highest rates of unintended pregnancy (USDHHS, 2012; Finer \& Henshaw, 2006), unintentional pregnancy has no social, socioeconomic, age or educational boundaries.

There are health and economic repercussions for those experiencing unintended pregnancy that choose to carry the pregnancy to term including an 
increased risk for maternal depression and an increased risk of physical violence during pregnancy (Logan et al, 2007; Cheng et al, 2009; Kost et al, 1998; D'Angelo et al, 2004). Children born from unintentional pregnancies are more likely to experience birth defects and below average birth weights, have lower educational attainment and have more behavioral issues in their teen years (CDC, 2006; Logan et al, 2007). In all, the more adolescents learn to manage their reproductive health and protect themselves during sexual activities, the less likely they are to experience an unintended pregnancy as an adolescent or as an adult.

Contraceptive use is influenced by multiple factors, including personal experiences. Matteson, Peipert, Allsworth, Phipps, and Redding (2006) conducted a randomized trial in females between the ages of $14-25$ to determine if women with a past experience of unplanned pregnancy were more likely to use contraceptives when compared to those without this experience. Contradicting the researchers' hypothesis, it was found that past unplanned pregnancy was not associated with overall contraceptive method use (Matteson et al., 2006). The study also revealed that $34 \%$ of the population stated they wanted to avoid pregnancy in the upcoming two years but were using no method of contraception (Matteson et al., 2006). The results highlight some of the major issues that exist when health care providers are addressing contraceptive use in women. Their previous experiences with unintended pregnancy may have little bearing on their current contraceptive use, and their intentions are not always in alignment with their actions. The study illustrates the potential complexity in the decision- 
making process involved with the use of contraception as well as the significance of studying this topic among adolescents. As effective methods of birth control are becoming more available in the United States, it is important to seek a better understanding of the forces deterring adolescent females from consistently using birth control. This understanding could inform preventative strategies and improve the unintended pregnancy rate.

\section{Definition of Terms}

The following terms will be used throughout the dissertation and are defined below:

Contraceptive use is the use of one of the following methods or devices intended to prevent pregnancy: male/female condom, pill, patch, ring, shot, implant, or intrauterine device.

Successful contraceptive use is the consistent use of one of the aforementioned methods by a sexually active adolescent female for at least one year without the experience of an unplanned pregnancy.

\section{Organization of the Dissertation}

Chapter Two of this dissertation presents a critical review of the literature on CSE. The purposes of this review were to identify variables that contribute to CSE in adolescent females and to identify the optimal use of the CSS (Levinson, 1986) for future studies. The identification of variables that may improve CSE among adolescents is important to inform contraceptive counseling and help healthcare providers identify and address potential risk factors among this population. Additionally, the evaluation of literature on the best way to use the 
CSS to most comprehensively measure CSE is essential for researchers seeking to add to the body of knowledge on this topic as well as for health care providers who are interested in using this tool to inform their practice.

Chapter Three presents the results of a study conducted to examine the CSE of adolescent girls (ages 13-18) accessing reproductive health services at an urban family planning clinic and to evaluate the psychometric properties of the CSS. In this study, a sample of 180 sexually active adolescent females completed a demographic instrument, a medical instrument, the CSS and the Social Desirability Scale-17 (SDS-17) (Stober, 2001). Demographic and medical variables were evaluated along with the SDS-17 scores to identify any relationships with or predictors of CSE. Group differences were also evaluated based upon demographic and medical variable responses. Lastly, Cronbach's alpha was generated to examine the reliability of the CSS and Exploratory Factor Analysis was generated and evaluated to determine the factor structure that best fits the CSS. Recommendations for future research, practice, and possible revisions to the CSS are provided in this chapter.

In Chapter Four, a study is presented in which adolescent girls who were successful contraceptive users (positive deviants) were explored qualitatively to evaluate similarities and differences among them as well as to determine how they navigate external influences to become successful contraceptive users. Ten sexually active adolescent girls who were participants in the study presented in Chapter Three, but who had also been successful using birth control for at least one year, completed an in-person, semi-structured interview. During this 
interview, participants were asked about variables found in research literature to influence adolescent sexual behavior. Participants were asked questions related to the following variables: CSE, gender roles, media influence, motivation to use contraception, parental influence, peer influence, religion, sex education received in school, and sexual pressure. Similarities and differences are presented as well as a theoretical framework describing how adolescent girls become positive deviants. Recommendations for future research, practice, and public policy are presented in this chapter.

Chapter Five provides an overview of Chapters Two through Four; a summary integrating the findings of the three manuscripts. Recommendations for future research, interventions, practice and public policy are included. 


\section{CHAPTER II \\ CONTRACEPTIVE SELF-EFFICACY: A CRITICAL REVIEW OF THE LITERATURE}

The teen pregnancy rate in the United States is alarming as it continues to rank higher than most other developed nations in the world (Guttmacher, 2016; Kost \& Henshaw, 2014; McKay \& Barrett, 2010; Nicoletti, 2004; USDHHS, 2012). Annually, in the United States, over 600,000 girls between the ages of 15-19 become pregnant, $82 \%$ of these pregnancies are reported as unplanned (Finer \& Zolna, 2011; Kost \& Henshaw, 2014; McKay \& Barrett, 2010). In 2012, almost half $(47.4 \%)$ of high school students in the United States reported having sex, but only $60.2 \%$ of sexually active students reported the use of a condom during their last sexual encounter (CDC, 2012). In Kentucky, the risk to adolescents for unintended pregnancy is even more substantial. Over half of Kentucky high school students reported being sexually active (51.8\%), and less than half of all sexually active students reported the use of a condom during their last sexual encounter (CDC, 2015) This phenomenon has only been studied minimally although it has the potential to significantly impact the reproductive health of adolescents. Research about adolescent contraceptive behavior must take a higher priority considering that the reproductive health habits learned as an adolescent can impact risk factors entering adulthood and beyond (Committee on 
Adolescence, 2007). In the pursuit of decreasing adolescent unintended pregnancy, one concept that is being evaluated in the research literature is Contraceptive Self-Efficacy.

Contraceptive Self-Efficacy (CSE) is defined as the strength of a young woman's conviction that she should and could exercise control within sexual and contraceptive situations to prevent an unintended pregnancy, if that is what she desires (Levinson, 1984). This concept was developed to evaluate and measure the theory of self-efficacy in the reproductive health realm in order to explain variations in the contraceptive use of adolescent girls, particularly among girls who say they do not want to become pregnant. The Contraceptive Self-Efficacy Scale (CSS) was developed to measure the CSE concept (Levinson, 1986). It was developed from family planning, psychology and social psychology research to explain why many young women, who say they do not want to become pregnant, fail to use contraceptives effectively and consistently, and to distinguish between successful and unsuccessful contraceptive users (Levinson, 1986).

The CSS is a patient self-report instrument that consists of 18 situational items that participants rate from 1 (not at all true of me), to 5 (completely true of me) (Levinson, 1986; Levinson, Wan \& Beamer, 1998). It has been found to be valid, reliable, and internally consistent (Ip et al., 2009; Levinson, 1995; Levinson, Wan \& Beamer, 1998; Longmore et al., 2003). Factor analysis in a previous study has revealed four factors accounting for $45.1 \%$ of the variance in contraceptive use and were labeled as follows: conscious acceptance of sexual 
activity by planning for it, assumption of responsibility for the direction of sexual activity and contraceptive use, assertiveness in preventing intercourse in an involved situation, and strong feelings of sexual arousal (Levinson, 1986). Cronbach's alpha for the instrument was .73 (Levinson, 1986). When using the CSS, the total instrument score has been found to be the best predictor of contraceptive behavior, but Levinson, Wan and Beamer (1998) also recommend that each item on the CSS be examined separately for a more complete understanding of the variations in contraceptive behavior among the population under study. The purposes of this article are to review the current body of knowledge on CSE in adolescent and young adult females and to 1) identify factors which contribute to the development and maintenance of improved CSE, and 2) to explore the optimal use of the Contraceptive Self-Efficacy Scale (CSS).

\section{Methods}

Literature Search Strategy

The literature for this critical review was found by searching the following four databases: CINAHL, Medline (Pubmed), PsychInfo, and the University of Louisville WorldCat. A variety of combinations, including the following search terms, were used: contraceptive self-efficacy, adolescent, female, and contraception. Searches were limited to the following time period: 1984-2016 (year of Levinson's initial publication on CSE to the present). Searches were limited to English language and peer reviewed articles or theses/dissertations. No geographic parameters were placed on the searches. A total of 115 studies were initially collected from the four databases. The title and abstract of each 
article were reviewed against the following criteria: whether 1) Levinson's Contraceptive Self-Efficacy Scale (CSS) (1986) was used and 2) the study sample included females. Studies that examined CSE using instruments other than the CSS were excluded as the use of other instruments makes it difficult to draw accurate comparisons across studies. Nine articles met the inclusion criteria and were critically reviewed. An additional five theses/dissertations were collected during the search. One was inaccessible; therefore, four theses/dissertations were also included in the critical review. A total of 13 manuscripts were reviewed for the following: purpose, sample, results and recommendations, and are summarized in Table 1.

\section{Results}

The majority of the manuscripts reviewed were cross-sectional studies; only one included data from a longitudinal study using a previously collected dataset. Sample sizes varied across studies and ranged from 15 participants to 3,577 participants who were predominantly Caucasian females between the ages of 12-45. A large majority of the study participants were recruited from family planning clinics. Other recruitment locations included secondary schools, colleges/universities, Child Protective Services facilities and hospitals.

\section{Contraceptive Self-Efficacy}

The connection between CSE and contraceptive use was supported in each study reviewed. Contraceptive self-efficacy is related to and predictive of contraceptive use, therefore, adolescent girls with higher levels of CSE act accordingly by utilizing contraceptives (Aitken, 2003; Heinrich, 1993; Hovsepian 
et al., 2010; Ip et al., 2009; Levinson, 1986; Levinson, 1995; Levinson, Wan \& Beamer, 1998; Longmore et al., 2003; Magoun Moreno, 2000; Peshkin, 1991; Van den Bossche \& Rubinson, 1997; Yosha, 2008). In regards to the CSS, effective or consistent contraceptive users report higher scores on the CSS, while ineffective or inconsistent contraceptive users report lower scores (Heinrich, 1993; Levinson, 1995; Levinson et al., 1998; Aitken, 2003; Magoun Moreno, 2000; Peshkin, 1991). Multiple authors suggest intervening by providing reproductive health education focused on increasing CSE among adolescents in order to increase their consistency in using contraception (Aitken, 2003; Hovsepian et al., 2010; Ip et al., 2009; Levinson, 1984; Levinson, 1986; Peskin, 1991). In all, CSE has consistently been found to be an important factor in the contraceptive behaviors of adolescent females.

Factors Influencing Contraceptive Self-Efficacy

\section{Demographic Variables}

In the theory of self-efficacy, Bandura (1977) contends there are several external factors that contribute to the development and maintenance of a woman's self-efficacy. This statement appears to be consistent in the critically reviewed research on CSE. The following demographic and social influences have been found to be related to improved CSE in the critically reviewed research: greater age, identifying as Caucasian or Latino, living with a stepparent, having a mother who approves of adolescent contraceptive use, sexual relationship stability and increased maternal education (Heinrich, 1993; 
Hovsepian et al., 2010; Ip, et al., 2009; Longmore et al., 2003; Aitken, 2003; Magoun Moreno, 2000).

Age was correlated with CSE suggesting that the older one gets, the more CSE he or she has (Heinrich, 1993; Longmore et al., 2003; Magoun Moreno, 2010). Findings related to race have been inconsistent. While some studies have found that there is no significant relationship between race and CSE, others have found that girls who identified themselves as Caucasian or Latino had more CSE than their peers who did not (Longmore et al., 2003; Magoun Moreno, 2000). Girls who reside with a step-parent as well as girls whose mothers approve of contraceptive use had higher levels of CSE suggesting that with whom one lives as well as their attitudes about adolescent birth control use may influence adolescent contraceptive behavior (Longmore et al., 2003; Magoun Moreno, 2000). Participants who were married or in stable, consistent sexual relationships with one partner had higher levels of CSE, suggesting that women in committed relationships feel more in control of what happens to them as it relates to sex and contraception (Ip et al., 2009). Girls whose mothers had not completed high school had less CSE suggesting that the more educated one's mother is, the more likely she perceives control over herself in sexual and contraceptive situations (Longmore et al., 2003).

\section{Personality Traits}

An individual's personality characteristics can influence her contraceptive behavior. CSE was related to and may be predictive of certain personality characteristics such as conscientiousness and neuroticism (Aitken, 2003). Study 
participants who were highly conscientious perceived that they were solely responsible for their sexual behaviors. These participants were more likely than their peers to use contraception consistently. On the contrary, study participants who scored high on neuroticism scales felt less in control of their sexual behaviors. These participants were less likely than their peers to use contraception consistently (Aitken, 2003).

\section{Life Experiences}

Life experiences and social behaviors may have an influence on the CSE and contraceptive use of adolescent females. Specifically, alcohol use and abuse were significantly related to CSE and contraceptive use (Aitken, 2003). The frequency of alcohol consumption and the amount of alcohol consumed was significantly related to whether or not girls had sexual intercourse as well as the frequency of sexual intercourse without the use of contraception. Women consuming alcohol frequently were less efficacious with contraception than their peers who did not.

Additionally, the experience of sexual abuse in early childhood was negatively associated with an adolescent girl's ability to communicate about sexual things (Hovsepian et al., 2010). This inability to communicate effectively in sexual situations may negatively impact CSE and, in turn, an adolescent girl's consistent use of contraception. Likewise, the experience of sexual coercion in a past dating relationship was negatively associated with an adolescent girl's perceived ability to communicate about sexual things, perceived control over her 
sexual activities, and the level at which she believed she could control the use of contraceptives in a sexually aroused situation (Hovsepian, 2010).

Lastly, the experience of past pregnancy and termination of pregnancy were not significantly related to CSE, suggesting that experiences of previous unintended pregnancies may not significantly impact the contraceptive use of adolescent females (Ip et al., 2009; Yosha, 2008). Yosha (2008) reported that girls who had experienced an unintended pregnancy and termination of pregnancy had similar CSE scores to their counterparts without this experience. These studies demonstrate that individual life experiences may influence an adolescent girl's CSE, but the level of influence may vary from person to person and from situation to situation.

Optimal Use of the CSS

The CSS is an internally consistent and reliable instrument that has been recommended for use in the evaluation of CSE (Levinson, Wan and Beamer, 1998). Since its development, recommendations for optimal use of the CSS have evolved. After critical review of the literature, and low reliability coefficients on versions of the CSS with a 3-point Likert scale (Levinson, Wan, \& Beamer, 1998) it appears that the CSS, as originally published (Levinson, 1986) with 18 items and a 5-point Likert scale, should be used when evaluating CSE. The CSS total item score should be evaluated to describe the overall CSE of an individual or study sample. Additionally, Levinson, Wan and Beamer (1998) recommend that the individual item scores be considered because each item explains a unique aspect of the variance in contraceptive use and could add more insight 
into the CSE of the population under study. Lastly, the evaluation of the identified factors of the CSS as subscales or domains may result in additional insight into the needs of the person or population being studied, particularly when seeking to develop interventions targeting the specific needs of a group (Horsepian, et al., 2010; Yosha, 2008).

\section{Critique of the Literature}

The literature reviewed in this paper has built the foundation for what is known about CSE as a theoretical framework, however it also highlights areas that require further exploration and increased attention to detail in future studies. Overall, there was a lack of diversity in the studies that have explored CSE thus far. Most of the study samples included populations who were predominantly Caucasian (Aitken, 2003; Heinrich, 1993; Hovsepian et al., 2010; Levinson, 1986; Levinson, Wan \& Beamer, 1998; Peshkin, 1991). Only one study to date has used the CSS outside of North America (Ip et al., 2009). It is important to note that girls from different cultural and ethnic backgrounds may have different motivations for becoming sexually active and using contraception, and may therefore experience different levels of CSE. Future research must attempt to study more diverse samples. Further, Levinson, Wan and Beamer (1998) attempted to provide normative scoring for the CSS, but three of the four samples studied (Sunnyvale, college students and Montreal) consisted of predominantly Caucasian participants. There were also very few participants in

the study samples who self-identified as Hispanic, Asian or "Other." Considering 
this, it is inappropriate to assume that these normative scores would be consistent or applicable across racial and cultural groups.

While Levinson, Wan and Beamer (1998) describe the most comprehensive way to use of the CSS (examining the total CSS score and individual item scores), none of the literature since that publication has followed those recommendations. This is a significant limitation in research using the CSS because the results may not provide the most comprehensive evaluation of CSE in the population being studied. Additionally, the assertions made based upon such incomplete data should be considered with caution.

When evaluating the instruments used in each study reviewed, it was noted that manuscripts evaluating the psychometrics of the original CSS had adequate statistical power and the CSS was deemed reliable with Cronbach's alpha $=.73$ (Levinson, 1986). Several studies reviewed, however, reported the use of altered, abbreviated or translated versions of the CSS with reliability coefficients that were either unacceptable or omitted entirely (Ip et al., 2009; Levinson, Wan and Beamer, 1998; Longmore et al., 2003; Peshkin, 1991; Van den Bossche \& Rubinson, 1997). Longmore and colleagues (2003) reported using three items from the CSS with the original 5-point Likert scale. The reliability coefficient given for this three item instrument was .61 which is unacceptable. Assertions made in this study related to CSE may not be comparable to those using the full CSS. Using an unreliable instrument presents a threat to the internal validity of the study. 
The CSS was translated into Chinese by Ip and colleagues (2009) with a reported Cronbach's alpha of .65. Another study (Levinson, Wan \& Beamer, 1998) noted the use of the original 18 -item CSS with a three-point Likert scale instead of the original five-point response scale. Additionally, in this study, a French version of the CSS was used in Canada and there was no reported psychometric evaluation. One must use caution when comparing the raw scores and statistics between these studies. Several other times, it was noted in the literature that a modified version of the CSS was used but it was not clear how it had been modified nor if the instrument had been evaluated for reliability or validity (Levinson, Wan \& Beamer, 1998; Peshkin, 1991; Van den Bossche \& Rubinson, 1997). Future studies using an altered version of the CSS should include a psychometric evaluation of that instrument and ensure its' reliability and validity.

Beyond the limitations related to instrumentation, each of the study samples were selected via convenience sampling. This prevents the generalization of these results to other populations and must be considered when interpreting study results. Lastly, the CSS measures sensitive information via self-report. Social desirability is a concept describing the tendency of respondents to give overly positive self-descriptions on scale items (Edwards, 1957). When subjects record socially desirable answers instead of their true responses, the results of the study may be significantly skewed. Considering the sensitive nature of the information collected on the CSS, social desirability may be an important factor to consider in an attempt ensure the accuracy of the 
collected data. In studies evaluating CSE, it is appropriate and of interest to examine social desirability as a covariate. To date, this has not been done.

\section{Discussion}

Contraceptive self-efficacy is a theoretical framework that has been found to have great influence on the contraceptive use of adolescent girls. The results from this critical review of the literature indicate that there are external influences on the CSE of young women which is in line with the verbal persuasion and vicarious experience components of self-efficacy theory (Bandura, 1977). Additionally, there are also internal influences (demographic characteristics) that also influence the CSE of young women. The results from this review have implications for research and clinical practice.

Implications for Research

Future research should continue to explore the CSE of diverse populations in an attempt to establish reliable, normative scoring matrices for the CSS. Studies should use the scale in the recommended, most comprehensive way; evaluating both the total instrument score and individual item scores. This will allow researchers to describe the CSE of each individual or study sample completely, allowing for deeper understanding of the variation in contraceptive use among adolescent females. Additionally, qualitative studies exploring other factors that influence contraceptive self-efficacy and studies purposely including participants from under-represented ethnic/racial minority groups may help to identify the $55 \%$ of the variance in contraceptive use that remains unexplained by the CSS (Heinrich, 1993; Levinson, 1986; Levinson, 1995). Identification of 
variables that impact this variance are critical for the development of interventions to promote consistent contraceptive use and reduce unintended pregnancies among adolescents. It may also be of interest for future research to explore other life experiences to determine which experiences appear to influence CSE and contraceptive use and which ones do not.

Implications for Practice

Current literature supports a focus on CSE in clinical practice to help improve contraceptive use among adolescents (Hovsepian et al., 2010; Ip et al., 2009; Levinson, 1984). Strengthening an adolescent girls' belief that she can be a consistent and successful user of contraception can have profound effects on her reproductive health behaviors and risk factors (Heinrich, 1993; Ip et al., 2009; Levinson, 1986; Magoun Moreno, 2000; Peshkin, 1991). Considering this, health care providers should consider using the CSS in clinical practice environments to inform their contraceptive counseling sessions. Evaluating the overall score on the CSS and individual item scores may identify potential risks that need to be addressed as well as present opportunities to provide patients with the skills they need to navigate reproductive health situations safely.

\section{Conclusion}

Contraceptive self-efficacy is a theoretical framework that, with additional research, has the potential to improve contraceptive use for both adolescent and adult females. Previous research supports the notion that CSE is a strong predictor of contraceptive use and may be influenced by multiple demographic variables. Further research on CSE is needed in more diverse and randomized 
samples. The CSS should be used comprehensively in all future studies of CSE. Further research is also needed to explore other factors accounting for the variance in contraceptive use among adolescent females. Such research could play a significant role in meeting the Healthy People 2020 goal of decreasing unintended pregnancies among adolescents in the United States (USDHHS, 2012). 
Table 1

Studies of Contraceptive Self-Efficacy in Females from 1984-2015

\begin{tabular}{|c|c|c|c|}
\hline Authors, Year & Purpose & Sample & Results/Recommendations \\
\hline $\begin{array}{l}\text { Aitken, } \\
\text { K.L, } \\
2003\end{array}$ & $\begin{array}{l}\text { Explore the } \\
\text { relationship between } \\
\text { personality } \\
\text { characteristics, CSE } \\
\text { and socio-sexual } \\
\text { orientation. }\end{array}$ & $\begin{array}{l}N=131 \text { females between } 16-18 \\
\text { years old recruited from three, } \\
\text { female-only secondary schools } \\
\text { ( } 2 \text { private, Christian institutions } \\
\text { and } 1 \text { public institution) who } \\
\text { were predominantly Caucasian } \\
\text { and of mid-high socio- } \\
\text { economic statuses }\end{array}$ & $\begin{array}{l}\text { - CSE was related to conscientiousness and } \\
\text { neuroticism. Those who were highly } \\
\text { conscientious perceived responsibility for their } \\
\text { sexual behaviors while those with high levels of } \\
\text { neuroticism felt less in control of their sexual } \\
\text { behavior. Each acted accordingly in respect to } \\
\text { their birth control use. } \\
\text { The frequency with which a participant drank } \\
\text { alcohol and how much they consumed was } \\
\text { significantly related to whether they had sexual } \\
\text { intercourse }(r=-.312, p<.05) \text {. }\end{array}$ \\
\hline
\end{tabular}

- CSE was significantly related to alcohol misuse, frequency of intercourse without using contraception $(r=-.313, p<.05)$.

- CSE was an important predictor of contraceptive use, personality characteristics and alcohol use.

$\begin{array}{lll}\text { Heinrich } & \text { Examine the } & N=250 \text { females ages } 17-25 \\ \text { L.B, } & \text { relationship between } & \text { attending a mid-size university } \\ 1993 & \text { CSE and contraceptive } & \text { who were predominantly } \\ & \text { use. } & \text { Caucasian, unmarried and } \\ & & \text { sexually active }\end{array}$

- CSE was significantly correlated with effective contraceptive use $(r=0.4, p<0.01)$.

- CSE was the most important predictor of contraceptive use while the woman's knowledge about contraception and lack of perceived barriers were also important factors.

- Age was significantly correlated with effective contraceptive use $\left(x^{2}=4.08, p=0.04\right)$. 
Hovsep-

ian et

al., 2010

Ip et al., 2009
Explore associations

between prior

victimization and

sexual and

contraceptive efficacy

among adolescents

under the care of Child

Protective Services as

the secondary part of a

study aimed to

document

psychosexual profiles,

risks and protective

factors among this

group.

Determine if

contraceptive

knowledge and CSE

predict contraceptive

behavior in Hong

Kong Chinese women.
$N=328$ females between $12-18$ years old who were under the care of Child Protective

Services in Quebec, Canada.

\section{$N=117$ Chinese women}

between ages $16-45$ recruited from the gynecology unit of a public teaching hospital and from Family Planning

Association clinics in Hong Kong.
- Mean CSE score=4.07

- Consistent contraceptive users had higher CSE scores than less consistent users.

- Author recommends qualitative inquiry to explore which additional variables account for the $55 \%$ of the variance in contraceptive use not explained by the CSS.
- $\quad$ Mean CSE score $=3.13$

- There were no significant relationships found between contraceptive knowledge and contraceptive use, between CSE and contraceptive knowledge or between CSE and history of pregnancy and termination.

- $\quad$ Age and marital status were the only sociodemographic variables significantly related to CSE.

- $\quad$ Single participants scored significantly lower than their married counterparts.

- Authors suggest that programming and clinical education programs that are focused on increasing CSE rather than on increasing contraceptive knowledge will be most beneficial in decreasing unintended pregnancy.

- Women with more stable, ongoing sexual relationships with one partner had higher levels of CSE. 
Levin-

son,

1984

Levin-

son,

1986

\section{Levin-}

son,

1995
To further develop the

CSE concept and

identify sexual and

contraceptive issues

for a group of

adolescents.

Development of the

CSS as an instrument

to measure the

extension of self-

efficacy in the

reproductive health

realm.

-Explore the factor

structure and reliability

of the CSS.
$N=15$ Latin American children attending a school for juvenile delinquents, primarily low income, and sexually active
- Interventions focused on CSE can influence contraceptive behaviors by increasing consistent contraceptive use.
$N=258$ females ages 20 or younger at a family planning clinic who were predominantly

Caucasian and considered at

high risk for pregnancy
- The CSS had 4 factors that accounted for $45.1 \%$ of the variance in contraceptive use:

- Conscious acceptance of sexual activity by planning for it (6 items)

- Assumption of responsibility for the direction of sexual activity and contraceptive use (4 items)

- Assertiveness in preventing intercourse in an involved situation (3 items)

- Strong feelings of sexual arousal (5 items)

- Cronbach's alpha=.73

- Interventions aimed at improving CSE can motivate teen girls to consistently use contraception or abstain from sexual intercourse.
$N=521$ girls ages 20 or younger recruited from two family planning clinics (263 in Chicago, IL and 258 in Sunnyvale, CA)
Investigate the relationship between

CSE, reproductive and contraceptive knowledge (RCK) and contraceptive behavior.
- There was no significant relationship between RCK and contraceptive behavior.

- Knowledge of contraceptive/reproductive health did not predict contraceptive use.

- CSE accounts for $45 \%$ of the variance in women's contraceptive use; the other $55 \%$ should be explored further in future research. 
Levin-

son et

al., 1998

Long-

more et

al., 2003

Magoun

Moreno,

A.M.,

2000
Further develop the CSS and explore its most advantageous use.

Explore the CSE and contraceptive use of adolescent boys and girls after one year using data from two waves of the National Longitudinal Study of Adolescent Health collected in 1994

Examine the impact of mother-daughter relational variables upon the responsible contraceptive use of female, college-aged students.
4 samples in the United States and Canada

-Family planning clinic in

Chicago, IL $(N=259$, mean age $=17.2$ )

-Family planning clinic in

Sunnyvale, CA $(N=258$, mean age $=17.6$ )

-High school in Montreal,

Canada $(N=231$, mean

age=15.9)

-College in northeastern USA

$(N=148$, mean age $=18.5)$

$N=3577$ boys and girls collected from students between $7-12^{\text {th }}$ grade who were at least 15 years of age and selfreportedly sexually experienced

$N=123$ females between $18-24$ years old recruited from colleges and universities in southern California and were single, had a living mother with whom she lived for at least $80 \%$ of the time before her $18^{\text {th }}$ birthday, and had been sexually birthday, and had been sexually active with a male in the last 6 months.
- Total scores on the CSS were significant predictors of contraceptive behaviors in all four samples.

- Each item on the CSS has unique variance in the definition of CSE and should be treated as a predictor in its own right

- Correlations between the items on the scale were low.

- The CSS was internally consistent $(\mathrm{p}<.05)$ and recommended for use in the evaluation of CSE.

- Item means, normalization and standard deviations are presented based upon the scores of the 4 samples.

- In addition to the total CSE score, each item score should be examined separately for a better understanding of the variations in contraceptive behavior.

- Participants who were older, living with stepparents and whose mothers approved of the use of contraception reported higher levels of CSE.

- Girls with mothers who did not complete high school had less CSE

- Adolescent girls had more CSE than boys.

- CSE increased with age.

- Race/ethnicity and religious involvement were not significantly related to CSE.

- CSE was associated with responsible contraceptive use.

- Participants who were older, Latinas, and those perceiving their mothers as approving of premarital sex were more likely to be consistent and responsible contraceptive users. 
Peshkin,

F., 1991

Van den

Bossche,

F. \&

Rubin-

son, L.,

1997
Investigate the

relationship between

self-efficacy theory

and contraceptive

behaviors in a group of

late adolescents
$N=207$ predominantly

Caucasian, late adolescents

between 18-20 years old

(males=101, females=106) who

were sexually active, single,

had been involved with the

same sexual partner for at least

3 months and were enrolled at

the university under study

$N=207$ (101 males and 106 females) between 18-20 years old recruited from a local university the midwestern part of the United States
- CSE was the most important variable contributing to responsible sexual activity.

- Genders are influenced by CSE differently. 5 factors loaded for the female participants while 4 factors loaded for the males explaining 55.84\% of the variance and $54.74 \%$ of the variance respectively.

- The single most important variable in increasing CSE and contraceptive use among females was their level of confidence in their ability to prevent unwanted pregnancy. For males, it was their belief that using contraception is not an inconvenience.

- The CSE framework can be applied to males and should be used to evaluate and improve consistent contraceptive use across genders.

- Both sexes needed to develop better communication skills regarding contraceptive issues. Females scored low on items related to communicating about sexual matters and those related to securing contraceptives for use. Males scored low on items related to stopping sex if they are not going to talk about protection.

- Authors recommend that adolescent boys and girls be taught skills improving their ability to communicate with sexual partners about contraception and other reproductive issues. 
Yosha,

A.M.

2008
Examine the CSE of

female adolescents

seeking elective

terminations in

comparison to the CSE

of their sexually active

peers who were

seeking other

reproductive health

services.
$N=176$ females between 13-21

years old recruited from an

urban family planning clinic

who were single and had

experienced sexual intercourse

at least once.
- Participants presenting for termination services did not have lower CSE scores than other participants.

- Girls seeking terminations scored lower on the "prevention of unprotected intercourse" factor than all other participants. 


\section{CHAPTER III \\ URBAN ADOLESCENT FEMALES: CONTRACEPTIVE SELF-EFFICACY AND THE \\ CONTRACEPTIVE SELF-EFFICACY SCALE}

\section{Introduction}

The United States has the highest rate of teenage pregnancy among all developed nations, a phenomenon that is not well understood. Behavioral patterns established during the adolescent and young adult years help to determine young people's health status and overall health risks as they enter adulthood (USDHHS, 2012). This suggests that if teens develop poor reproductive health habits, they are likely to continue these habits into adulthood, incurring more risks. This is an issue of great magnitude in the United States today. The Youth Risk Behavior Surveillance survey performed by the Centers for Disease Control and Prevention (CDC) (2012) demonstrates that a large number of high school students are sexually active. Nationally, in $2012,47.4 \%$ of high school students had experienced sex; an increase from $46 \%$ reported in the 2009 survey (CDC, 2009). Additionally, the percentage of sexually active students that reported using a condom during their last sexual encounter had decreased to $60.2 \%$ from $63 \%$. This increase in sexual activity among adolescents coupled with a decrease in use of contraception has ultimately resulted in approximately 615,000 girls between $15-19$ years of age becoming 
pregnant each year (Kost \& Henshaw, 2014). Eighty-two percent of pregnancies occurring annually among American teens are unplanned (Finer \& Zolna, 2011) suggesting that American teens are not using birth control consistently and effectively, if at all.

Teens in the United States are less likely than teens in other countries to use available methods of birth control although their levels of sexual activity are similar (Nicoletti, 2004; Kearney \& Levine, 2012; Santelli, Sandfort \& Orr, 2008). Noted as an important public health and social problem, teen pregnancy, unintended pregnancy, and sexually transmitted infections are issues that either peak or start during the critical adolescent years (USDHHS, 2012), and are directly impacted by teens' inconsistent or nonexistent contraceptive use. The Committee on Adolescence (2007) noted that births to adolescents remain both an individual issue and a public health issue; as such, they determined that health care providers have the responsibility to assist teens in decreasing the risks related to adolescent sexual behaviors.

As methods of birth control become more accessible, it is important to understand the variables preventing adolescent females from consistently using contraception. Understanding these variables could improve prevention strategies focused on decreasing risky adolescent sexual behaviors and preventing unintended pregnancy.

\section{Contraceptive Self-Efficacy}

It has been proposed that an extension of the theory of self-efficacy, contraceptive self-efficacy (CSE), can be applied to explain and possibly 
address unintended teenage pregnancy (Levinson, 1984; Levinson, 1986). Contraceptive Self-Efficacy (CSE) is the strength of a young woman's conviction that she should and could exercise control within sexual and contraceptive situations to achieve a contraceptive priority, if that is her desire (Levinson, 1984). In the context of this research, a contraceptive priority means that regardless of the situation in which an adolescent girl finds herself, using contraception to prevent an unintended pregnancy is her first and main goal. CSE is a theoretical framework developed to extend the theory of self-efficacy into the realm of reproductive health. The theory of self-efficacy has been used across numerous disciplines, including nursing (Resnick, 2008). The theory was derived from social cognitive theory as a way to produce and predict behavior change in individuals (Bandura, 1977). It assumes that the way people think, believe and feel affects how they behave, and that psychological procedures and interventions aimed to alter those thoughts, beliefs, and feelings can result in behavior change. The central assumption of this theory is that people can exercise control or influence over what they do (Bandura, 1977). Bandura (1977) found that an individual's self-perception and ability to perform desirably in any given situation is influenced by several factors, some of which are external, or beyond the control of the individual. The theory of self-efficacy acknowledges that various components of each woman's lived experience impacts her decision-making and behavior (Bandura, 1986). It has been used successfully to predict the process of behavior change as well as to 
motivate persons to engage in health promoting activities (Bandura, 1977; Resnick, 2008).

Previous research highlights the significant role of self-efficacy in behavior change across select populations. In adolescents as a general population, and in particular with adolescent females, self-efficacy has been found to play a major role in decision-making related to risk behaviors, especially related to contraceptive use. Literature continues to support the influence of CSE on contraceptive behavior in adolescent girls and adult women alike. Contraceptive self-efficacy has been found to be the most important predictor of contraceptive use (Aitken, 2003; Heinrich, 1993; Hovsepian et al., 2010; Ip et al., 2009; Levinson, Wan and Beamer, 1998; Magoun Moreno, 2000; Wright, 1992; Yosha, 2008). As CSE increases, contraceptive use also increases (Aitken, 2003; Levinson, Wan \& Beamer, 1998; Magoun Moreno, 2000; Wright, 1992;).

According to Bandura (1977) four external resources contribute to the development and maintenance of an adolescent girl's CSE including enactive attainment, vicarious experience, verbal persuasion, and physiological feedback. Enactive attainment refers to an individual actually performing the behavior in question, and has been noted as the most influential resource in self-efficacy development (Bandura, 1977). Vicarious experience is the resource that refers to an individual seeing other persons performing a desired activity (Bandura, 1997). If individuals are presented with a behavior that they must enact, they will be more likely to have confidence that it can be achieved if they have seen 
someone else successfully achieve it. Verbal persuasion involves verbalizing to an individual that he or she has the capabilities to complete the given behavior (Bandura, 1977). Lastly, the resource known as physiological feedback or emotional arousal refers to an individual's physical responses to a given action or behavior (Bandura, 1977). In combination, each of these resources contributes to the development and maintenance of an individual's self-efficacy.

Previous studies have found that several external variables may impact an adolescent's contraceptive self-efficacy. These variables include age, the people with whom the adolescent lives, mother's approval or disapproval of contraceptive use, mother's level of education, gender roles, and the adolescent's employment status (Levinson, 1995; Longmore, Manning, Giordano, \& Rudolph, 2003; Ip, Sin, \& Chan, 2009; Heinrich, 1993; Van den Bosche \& Rubinson, 1998). Thus, research demonstrates the need to evaluate demographic variables and their relation to contraceptive self-efficacy. See Figure 1 for a depiction of the CSE theoretical framework.

The Contraceptive Self-Efficacy Scale (CSS) was developed to measure CSE (Levinson, 1986). The scale was developed from research in the disciplines of family planning, psychology and social psychology to explain why many sexually active young women, who say they do not want to become pregnant, fail to use contraceptives effectively and consistently (Levinson, 1986). It was developed to gain understanding about those factors which seem to account for the difference in young girls' behavior in dealing with sexual activity (Levinson, 1986). The CSS has been found to be reliable (Cronbach's alpha=.73, Levinson, 
1986) and internally consistent (Ip et al., 2009; Levinson, 1995; Levinson, Wan \& Beamer, 1998; Longmore et al., 2003). To further develop the CSS, Levinson, Wan and Beamer (1998) explored its' use in four diverse samples in the United States and Canada. In this study, it was found that the total CSS score, in particular, was the best predictor of contraceptive behavior in all four samples. It was also noted that each item on the CSS has unique variance in the definition of CSE which warranted treatment as a predictor of contraceptive behavior in its own right. Based on this study it was recommended that in addition to the total CSS score, scores on each item should be examined separately for a better understanding of the variations in contraceptive behavior among the population under study. To date, these recommendations have not been followed in any published study using the CSS.

Factor analysis in previous studies have indicated that scale items have relatively low correlations to one another (ranging between .09-.130 with an average of $0.15(p<.05))$ and that CSE uniquely predicts contraceptive use (Heinrich, 1993; Ip et al., 2009; Levinson, 1984; Levinson, 1986; Levinson, 1995, Levinson et al., 1998; Longmore et al., 2003). In the initial analysis of the CSS, Levinson and colleagues (1986) noted that the scale possibly had 5 factors, but for conceptual clarity, the four factor model was chosen. The four factors were labeled as follows: conscious acceptance of sexual activity by planning for it, assumption of responsibility for the direction of sexual activity and contraceptive use, assertiveness in preventing intercourse in an involved situation, and strong feelings of sexual arousal (Levinson, 1986). These factors accounted for $45.1 \%$ 
of the variance in contraceptive use. Cronbach's alpha for the instrument was .73 (Levinson, 1986). The instrument has been tested in groups of females in several locations: adolescents in California, adolescents in Chicago, Illinois, and high school students and college students in Montreal, Canada (Levinson et al., 1998). The scale was found to be internally consistent in the above populations and thus recommended for use in the evaluation of CSE (Levinson, Wan \& Beamer, 1998).

\section{Social Desirability}

A variable of interest when examining a sensitive topic such as CSE is social desirability. Social desirability is a concept based upon the original hypothesis of Edwards (1957) which states that scores on personality inventories could be largely accounted for by individual differences in the tendency to give socially desirable responses to items on the scale. Social desirability is typically defined as the tendency to give overly positive self-descriptions and has been applied to several concepts in research (Paulhus, 2002). In part, social desirability encompasses a type of impression management (Paulhus, 2002), where respondents answer items on research instruments in a way that creates a positive impression of themselves. It also includes one's agency and selfdeception, as the respondent may be unaware of his/her true thoughts, feelings and personality traits because they have deceived themselves into believing that they possess only socially desirable traits (Paulhus, 2002). Social desirability can therefore be a conscious or an unconscious occurrence; nevertheless, it can 
result in research findings that are biased and do not measure the intended variable.

Scores on social desirability scales measure the tendency of a respondent to give answers they believe to be desirable and socially acceptable to the society to which they belong (Wiggins, 1962). Additionally, Marlowe and Crowne (1964) noted that scores on a social desirability assessment represent an individual's need for approval which they considered to be a quantifiable personality trait. This need for approval indicates a person's desire to conform to the opinions and standards of the society in which they live; the desire to be socially desirable (Reynolds \& Juvonen, 2011). Persons high in need for social approval tend to care what others think and will change any given behavior to exude an image deemed socially acceptable and desirable (Reynolds \& Juvonen, 2011). Social desirability, the innate need for approval, can therefore greatly influence an individual's behavior in all social situations, including those related to family planning and contraceptive use. No previous research has determined whether a relationship exists between social desirability and contraceptive self-efficacy.

The purpose of this study was to examine the CSE of adolescent girls (ages 13-18) accessing reproductive health services at an urban family planning clinic, and to evaluate the psychometric properties of the CSS. The following specific aims and associated research questions were examined:

1. Explore factors that influence contraceptive self-efficacy (CSE) in adolescent females. 
a) What is the CSE of adolescent females seeking reproductive health services at an urban family planning clinic?

b) How do medical and demographic variables influence CSE?

c) Does social desirability influence CSE?

d) What factors best predict CSE?

e) What group differences exist in the CSE of adolescent females seeking reproductive health services?

2. Evaluate the dimensionality and internal consistency reliability of the Contraceptive Self-Efficacy Scale (CSS) in adolescent females seeking reproductive health services.

a) What are the psychometric qualities of the CSS in adolescent females seeking reproductive health services?

b) What factor structure best fits the CSS in adolescent females seeking reproductive health services?

\section{Methods}

\section{Study Population}

The convenience sample for this study included 180 adolescent girls requesting services at a local family planning clinic in a southern city in the United States. Clinic patients were invited to participate in the study if they were: 1) female, 2) between ages $13-18,3$ ) seeking reproductive health services at the clinic under study, 4) ever sexually active with a male partner, and 5) able to read and understand English. 


\section{Procedures}

The study was cross-sectional. Patient service specialists at the family planning clinic screened presenting patients against the eligibility criteria using the clinic's medical history form. When potential participants successfully met all criteria, the primary investigator was notified. Prior to the potential participants' scheduled appointment, the primary investigator met privately with eligible adolescents, explained the study and invited them to complete the surveys.

Once informed consent was obtained, the participants were given the demographic and medical instruments, the Contraceptive Self-Efficacy Scale, and the Social Desirability Scale-17 to complete prior to their clinic visit.

Procedures for this study were approved by the Institutional Review Board at a local university and the clinic's national research office.

\section{Measurements}

Each of the instruments used in the study are described below:

\section{Instrument 1: Demographic Characteristics. The following} demographic variables were assessed via self-report on an investigatordeveloped instrument: age, race, gender, marital status, level of education, employment status, current living situation, insurance status, how the adolescent got to the family planning clinic, reason for the visit, state of residence, and who was aware that she was using contraception. The Flesch-Kincaid reading level for this instrument was 4.7 .

Instrument 2: Medical Characteristics. The following medical variables were assessed via self-report on an investigator-developed instrument: history of 
pregnancy, age at first sexual encounter, sexual experience, frequency of sexual activity, current method of birth control, consistency of use of method, history of unprotected intercourse, and future plans for pregnancy. The Flesch-Kincaid reading level for this instrument was 5.1 .

Instrument 3: Contraceptive Self-Efficacy Scale. Levinson (1986) developed the reliable and valid contraceptive self-efficacy scale (CSS) as an instrument that would measure the extension of the theory of self-efficacy into the realm of reproductive health and contraception. The CSS is a patient self-report instrument that assesses motivational and efficacy-related barriers to contraceptive use among sexually active teenage girls (Levinson, Wan \& Beamer, 1998). CSE is assessed using 18 situational items that respondents rate from 1 (not at all true of me), to 5 (completely true of me). Scale statements assess a young woman's ability to: be assertive and prevent intercourse in a sexually involved situation, accept sexual activity by consciously planning for it (thinking about, talking about, and seeking contraception), positively accept the experience of sexual thoughts and feelings, and take responsibility for the direction of sexual activity and using birth control (Levinson, 1984; Levinson, 1986). Scale items were chosen to distinguish between successful and unsuccessful contraceptive users on the basis of personal, interpersonal, and environmental variables (Levinson, 1986). The four factors of the CSS each contain the following number of items: conscious acceptance of sexual activity by planning for it (6 items); assumption of responsibility for the direction of sexual activity and contraceptive use (4 items); assertiveness in preventing intercourse 
in an involved situation ( 3 items); and strong feelings of sexual arousal (5 items) (Levinson, 1986). The Flesch-Kincaid reading level for this instrument is 2.9.

Instrument 4: SDS-17. In 1999, Stober questioned if the items on the Marlowe-Crowne Social Desirability Scale (MCSDS), the most frequently used measure of social desirability, were still up-to-date. In particular, he noted that items describing behaviors, such as being courteous, reflected standards of the 1950 's and may no longer be relevant or reflect the standards of the current times. He decided to construct a new social desirability scale in the style of the MCSDS but with more up-to-date items and terminology (Stober, 2001). This new scale, the Social Desirability Scale-17 (SDS-17), originally contained 17 items, but one item asked about the use of illegal drugs and was removed due to item-total correlations close to zero and because a negative response would not necessarily indicate a socially desirable response in all persons (Stober, 2001). After multiple comparison studies, Stober (2001) concluded that the revised SDS-17, with 16 items was a reliable alternative to the MCSDS.

Since its creation, the SDS-17 has demonstrated convergent validity and discriminant validity when measured against the MCSDS (Stober, 2001). Although the scale was originally tested among young adults, its use is not restricted to this population (Stober, 2001; Tran, Stieger, \& Voracek, 2012). The SDS-17 has been examined psychometrically in five samples from Austria, Canada, and the United States $(n=2,817)$ and therefore found suitable for use in cross-cultural settings (Tran, Stieger, \& Voracek, 2012). Cronbach's alpha for this instrument has been reported to be 0.72 (Stober, 2001) and .70 (Tran, 
Stieger, \& Voracek, 2012). Psychometric evaluation of the SDS-17 has found that it is not unidimensional, but no studies have published factor analysis results identifying multiple factors (Tran, Stieger, \& Voracek, 2012). The Flesch-Kincaid reading level for this instrument is 5.8 .

\section{Data Analysis}

As surveys were collected, data were entered into Microsoft Access (Cox \& Lambert, 2013). When data collection from all 180 participants was completed, data were exported into IBM SPSS Version 22 (Arbuckle, 2013). Prior to any analysis, items $2,5,6,8,9,11,12,14$ and 15 on the CSS were reverse coded as indicated by Levinson (1986). Descriptive statistics were generated to assess the mean scores of the 180 subjects and describe overall contraceptive selfefficacy for this group of adolescent girls. Descriptive statistics were also evaluated to examine each item's mean score noting those with high and low scores. Demographic data from the descriptive statistics were then assessed to examine subgroups (age, ethnicity, etc.) and contraceptive self-efficacy by subgroup. Pearson's Product Moment Correlations and Point Bi-serial Correlations (when appropriate) were generated to assess relationships between variables collected from the demographic, medical forms, SDS-17, and overall CSE among this population. Additionally, t-tests and ANOVAs as well as post hoc analyses (Tukey) when appropriate were generated to observe differences in CSE related to demographic, medical, and social desirability data. An exploratory factor analysis was generated to examine the dimensionality of the CSS and Cronbach's alpha was generated to examine the internal consistency 
reliability of the CSS. Lastly, linear regression techniques were applied to explore the possibility of predicting CSE from one or more variables collected on the demographic, medical and SDS-17 forms. Variables were included in the model if they were previously found in the literature to influence CSE and/or if correlations in the current study identified significant relationships between the variable and CSE. Significance levels were set at $p<.05$ for all analyses.

\section{Results}

\section{Sample}

One hundred eighty adolescent females participated in the study, completing the demographic and medical instruments, the CSS and the SDS- 17. The sample identified themselves as $49 \%$ white and $41 \%$ black with a mean age of 16 years $(\mathrm{SD}=1.394)$, insured $(71 \%)$, unemployed $(61 \%)$, and presenting to the clinic for a birth control-related appointment (85\%). Only $41 \%$ of the sample reported using their chosen method of birth control correctly in the last month. $54 \%$ of the patients who seek services at the family planning clinic under study earn income at or below the federal poverty line, and $69 \%$ earn income at or below $150 \%$ of poverty (PPINK, 2016). Each adolescent recruited, chose to participate. Full demographic details of the study sample may be found in Table 2.

\section{Dimensionality of the CSS}

The CSS had good internal consistency and reliability; Cronbach's alpha for the CSS was .71 compared to .73 in Levinson's original study (1986). Responses on the CSS were factor analyzed to examine scale structure. Similar 
to findings by Levinson (1986), item correlations were relatively low, ranging between -.062-.483, with an average of .20 . Varimax rotation was selected due to the low correlations between items. Exploratory factor analysis revealed four, possibly five factors. Due to item loading coefficients and conceptual clarity, the four factor model was chosen. This model accounted for $50.4 \%$ of the variance in contraceptive use compared to $45.1 \%$ in Levinson's initial exploration (1986). While a few items loaded on different factors, the overall factor themes were consistent with Levinson (1986). Factor one appears to measure teenage girls' assumption of responsibility for the direction of sexual activity and for using contraception. Factor two measures assertiveness when preventing unprotected intercourse in a sexually involved situation. Factor three measures feelings of sexual arousal or an acceptance of one's sexual desires. Last, Factor four measures conscious acceptance of sexual activity by planning for it. The item loadings for each factor may be found in Table 2. Items \#11 and \#12 failed to load significantly on any of the four factors. Item \#11 loaded at .243 on Factor two and .247 on Factor four while item \#12 loaded at .137 on Factor one, .185 on Factor two, -.182 on Factor three and .239 on Factor four. Additionally, Cronbach's alpha did not decrease significantly if either item was deleted (.707 and .709 respectively). Each factor explained $22.9 \%, 10.8 \%, 9.7 \%$, and $7 \%$ of the variance in contraceptive use respectively. Item loadings for each factor as well as the item loadings for Levinson (1986) may be found in Table 3. 


\section{Contraceptive Self-Efficacy}

The overall CSE mean score for the study sample was $4.12(\mathrm{SD}=.549)$, compared to 3.91 which was the highest group mean in the study by Levinson, Wan and Beamer (1998). Item means were evaluated to assess those with high and low averages to further examine the CSE of the sample. Study participants scored the highest on items 15,9 , and $13 a$ (mean scores $=4.617,4.586$, and 4.534 respectively) indicating that this group of adolescent girls was able to be assertive with their sexual partners, reporting that they could stop sex from happening if they did not want it, they were able to say what they wanted in sexual situations, and they could bring up protection in the midst of being sexually aroused. In contrast, participants scored the lowest on items 2, 6, and 8 (mean scores $=3.46,3.582$, and 3.517 respectively) suggesting that the participants had difficulty discussing their true feelings related to sex, were less able to have sex easily when thinking about what it actually means, and that they may knowingly engage in unprotected sex because they were so emotionally or sexually involved in a situation. Item means and overall CSE scores may be found in Table 4.

Correlations were evaluated to assess any relationships between the CSE mean score and independent variables collected on the demographic and medical instruments or the SDS-17. Only seven variables were significantly correlated with the overall CSE mean, and none were highly correlated. Significantly correlated variables included: age $(r=.306, \mathrm{p}=<.0001)$, grade $(r=.295, \mathrm{p}=<.0001)$, partner knows that participant is using birth control $(r=.290$, 
$\mathrm{p}=<.0001)$, employment status $(r=.250, \mathrm{p}=<.0001)$, age at first sexual experience $(r=.204, \mathrm{p}=.003)$, male condom use $(r=.178, \mathrm{p}=.009)$, and SDS-17 score $(r=.177$, $\mathrm{p}=.009$ ). These correlations demonstrate that both demographic and medical variables influence the CSE of adolescent females. Additionally, social desirability is only minimally related to CSE suggesting it does not largely influence the CSE of adolescent girls. Correlated variables are listed in their entirety in Table 5.

Independent-sample t-tests and ANOVA's were conducted to compare CSE across responses on demographic variables, medical variables, and the SDS-17. Significant differences were noted in the following subgroups: age ( $F=$ 5.136, $\mathrm{p}=<.0001)$, race $(F=2.834, \mathrm{p}=.040)$, highest grade completed $(F=4.280$, $\mathrm{p}=<.0001)$, employment status $(t=-3.722, \mathrm{p}=<.0001)$, partner knows about birth control use $(t=-5.719, \mathrm{p}=<.0001)$, frequency of sex in the last month $(F=3.056$, $\mathrm{p}=.030)$, male condom use $(t=-2.397, \mathrm{p}=.018)$, and future pregnancy plans $(F=$ 4.006, $\mathrm{p}=.002)$ (Table 6).

Participants who were 17 years old had the highest raw CSE mean scores (4.25). Girls who were 15 years old had higher raw CSE mean scores than did 13,14 , and 16 year olds (mean scores $=4.12,3.40,3.77$, and 3.90 respectively). Statistically, there were significant variations in CSE based upon participants' age. Tukey post-hoc analysis revealed significant differences in scores between 13 and 17 year olds and between 13 and 18 year olds. Both 17 and 18 year olds had significantly higher CSE scores than their 13-year-old counterparts. This 
suggests that older girls see themselves as more in control of their sexuality and are more responsible in sexually charged situations than younger girls.

Participants identifying as white (4.18) had higher raw CSE mean scores than those identifying as black (3.98) or Hispanic (3.91). Participants identifying as "Other" had the highest raw mean score (4.52), however, there were only 6 participants that selected this option to identify their race. When examining raw mean scores, it appears that one's race may play a role in CSE. While ANOVA revealed a significant difference in means based upon participants' selected racial group ( $F=2.83, p=.04)$, Tukey post hoc analysis did not reveal statistically significant differences between any specific racial groups.

Consistent with age, girls who had completed higher grades also reported more contraceptive self-efficacy. Girls who had completed the $12^{\text {th }}$ grade had the highest raw CSE mean (4.21) suggesting that as girls age and increase their level of education, their CSE also increases. The more educated an adolescent girl is, the more likely she is to feel confident in her ability to be in control of sexual situations to achieve a contraceptive priority.

Girls who were currently employed (4.29) had significantly higher CSE mean scores than girls who were unemployed (3.98) $(t=-3.722, p<.0001)$. These results suggest that girls who are employed are more sexually responsible than their unemployed counterparts.

Girls whose sexual partners know that they are using birth control (4.43) reported more CSE than girls whose sexual partners did not know about their birth control use (3.99) ( $t=5.719, p<.0001)$. This suggests that girls who are open 
enough with their sexual partners to discuss birth control use and the prevention of an unplanned pregnancy are more likely to be responsible during the sex act.

Based upon ANOVA, there were also significant differences in the CSE of the study population based upon how frequently they had sex in the previous month ( $F=3.056, p=.030)$. Girls who had been sexually active four or more times in the previous month (sex $4-8 x$ mean score $=4.38$, sex more than $8 x$ mean score=4.29) had higher raw CSE mean scores than those who had sex less frequently (sex $1 x$ or less mean score $=4.04$, sex $2-3 x=3.97$ ). While this suggests that the more sexually experienced girls are, the more confident they are in their ability to protect themselves in sexual situations, Tukey post hoc analysis did not reveal significant differences based upon participant sexual frequency responses.

Girls reporting use of male condoms (4.20) had significantly higher CSE mean scores than girls who did not (3.98) $(\mathrm{t}=-2.397, p=.018)$. These results suggest that girls whose partners use condoms are more likely to feel like they can influence sexual situations by requesting the use of a condom from their sexual partners. Girls whose partners use condoms are more likely to have more CSE and thus are more likely to use birth control at every sexual encounter.

Last, there were significant differences in CSE depending upon when adolescent girls planned to become pregnant $(F=4.006, p=.002)$. When comparing raw mean scores, girls who were planning to become pregnant in the next year had the highest mean CSE score (4.31), followed by those who planned to get pregnant in five years or more (4.22). This suggests that girls who 
are planning a pregnancy in the near future as well as those who have planned to delay pregnancy for a significant amount of time are most confident in their ability to use birth control consistently. In essence, girls with a plan surrounding future procreation trust their ability to prevent pregnancy before it is planned. However, Tukey post hoc analysis revealed statistically different scores only between girls planning to get pregnant in 5 or more years and girls never planning to get pregnant. Complete mean score data with standard deviations, bivariates and significance levels are listed in Table 6 .

Linear regression techniques were employed to explore which, if any, of the variables found in the literature to influence risky sexual behaviors or any of the correlated variables from the demographic instrument, medical instrument or the SDS-17 score could be used to predict CSE. Using this criteria, the following variables were entered into the model as dichotomous variables using dummy codes as needed for continuous variables: age, grade, employment status, partner knows about birth control use, brother knows about birth control use, frequency of sex in the last month, proper use of chosen birth control method in the last month, male condom use, current birth control use, race (White, Black, Hispanic, Other), SDS-17 score, and plans for becoming pregnant (1 year, 2 years, 3 years, 4 years, 5 or more years, never plan to become pregnant). A significant predictive model including the following variables was developed: age, partner knows about birth control use, and plans to become pregnant in five or more years, and had an $R^{2}$ of $.211(F=15.54, p<.0001)$ for the prediction of contraceptive self-efficacy. The strongest predictor was plans for pregnancy in 
five or more years $(B=.245)$, followed by partner knows about birth control use $(B=.241)$ and age $(B=.232)$. Age, partners' knowledge of birth control use and plans for pregnancy in more than 5 years have significant, positive regression weights. This indicates that when girls age, when their partners are made aware of their contraceptive use and when their plans for pregnancy are greater than 5 years in the future, CSE scores are expected to be higher. This three predictor model accounted for $21.1 \%$ of the variance in CSE among this population, $F=15.54, \mathrm{p}<.0001, R^{2}=.211$ and was run frontward, backward, and stepwise for confirmation. Complete regression data is listed is Table 7.

\section{Discussion}

In order to gain a deeper understanding of the variables that influence the contraceptive self-efficacy and thus contraceptive use of adolescent females, the purpose of this study was to examine the CSE of adolescent girls (ages 13-18) accessing reproductive health services at an urban family planning clinic, and to evaluate the dimensionality of the CSS. Analysis of CSE in this population revealed an overall high level of contraceptive self-efficacy. This analysis also demonstrated that adolescent girls may be assertive when communicating with their sexual partners about sex and birth control and stopping sex if it is unwanted. However, they may be less interested in having sex when thinking about what it actually means and may be less able to stop unprotected sex in an emotionally charged or aroused situation. Beyond this, it was found that as girls age, they feel more in control of their sexual activities. Additionally, as girls become able to discuss their birth control method with their sexual partner, gain 
employment, and are sexually active more frequently, they become more efficacious, and thus more likely to engage in protected sex. Adolescent girls' use of male condoms during sexual encounters and their definitive future plans about pregnancy influence her contraceptive self-efficacy. Lastly, CSE can be predicted by the age of the adolescent girl, whether or not their sexual partner knows about her birth control use, and her future plans for pregnancy.

This study also sought to examine the relationship between CSE and social desirability. Results demonstrate that there is a minimal relationship between the two. This indicates that adolescents completing the CSS are not likely altering their responses according to what they think is socially desirable. This finding supports the reliability of the data collected in this study.

Several demographic and medical variables influence CSE including age, race, employment, and level of education. These findings support Levinson's previous work (Levinson, 1984; Levinson, 1986; Levinson, Wan \& Beamer, 1998). Further, the data from this study suggest that contraceptive use among adolescent females is complex and requires further exploration.

The results of the psychometric evaluation in this study were consistent with the results of Levinson's (1986) psychometric evaluation. This study supports the reliability of the CSS as well as its' continued use for the examination of CSE in adolescent females. Additionally, this study supports the four factor dimensionality of the CSS. While the overall factor structure in this study was very similar to that of Levinson (1986), the way the items loaded to each factor had a notable difference. As previously mentioned, there are items 
that loaded to different factors than in Levinson's (1986) study, but most significantly, there were two items (\#11 and \#12) that did not load very highly on any of the factors. This finding is of note because it suggests that these items do not fit cleanly into any of the factors and therefore could be removed (Plichta \& Kelvin, 2013; Waltz, Strickland \& Lenz, 2010). This finding requires further exploration.

\section{Implications}

This study has implications for both nursing research and nursing practice. Further research is needed to explore the impact of the variables found to be related with the CSE mean score. This study supports the assertion that demographic and medical variables influence CSE. Further research is also needed to examine the use of the CSS without items \#11 and \#12. This study indicates they could be removed without affecting the reliability or validity of the CSS. This shortened version of the instrument may allow researchers a more concise way to measure CSE in other populations. Further, it may be of interest for researchers to more meaningfully explore the characteristics of girls who are planning to get pregnant in one year and those planning to get pregnant in five years or more to explain their similarly high levels of CSE. A qualitative study is recommended to explore the similarities and differences of girls based upon their future plans for pregnancy. A study of this kind may identify characteristics that support the building of theories on adolescent contraceptive use and interventions focused on improving CSE among this population. Lastly, it may also be of interest for researchers to qualitatively explore the characteristics of 
adolescent girls who are employed to determine what makes them more sexually responsible than their unemployed counterparts of the same age.

These study results may inform clinical practice, particularly contraceptive counseling, in several ways. Only, $41 \%$ of the sample reported using their chosen method of birth control correctly in the last month, demonstrating that more than half of the adolescents participating were using their method incorrectly or inconsistently. This highlights the need for health care providers to ensure that each patient understands how to correctly use their contraceptive method before commencement and to troubleshoot any potential problems with using the method correctly (ex: setting a cell phone alarm to remember to take the birth control pill at the same time each day). This type of action may help prevent the likelihood of incorrect or inconsistent contraceptive use. Additionally, this finding supports the use of long-term contraceptive methods such as implants and intrauterine devices in adolescent girls. Adolescents in this study reported they may knowingly engage in unprotected sex because they were so emotionally or sexually involved in a situation. The use of long acting reversible contraceptive methods such as implants and intrauterine devices prevents this issue from becoming a factor in the development of unintended pregnancy in this population. Further, considering the relationship between sexual partners knowing about birth control use and CSE, it may be beneficial for healthcare providers to encourage adolescent girls to discuss their chosen method of birth control with their sexual partner prior to any sexual encounters. Discussing future plans for pregnancy may also encourage and empower adolescents to be 
more sexually responsible. In addition, it may be helpful for health care providers to have adolescents complete the CSS prior to starting a method of birth control in order to identify areas that require further counseling or skill building such as talking about birth control with a partner or coming to terms with or acceptance of one's sexual thoughts and desires. Lastly, study results can inform the development of interventions focused on increasing contraceptive self-efficacy among adolescent females. Interventions that establish communication skills related to sex and contraception and the increased use of condoms can improve CSE among this population and decrease the unintended pregnancy rate.

\section{Limitations}

Although this study adds to the body of literature on contraceptive selfefficacy and adolescent contraceptive behavior, it is not without limitations. This study was not randomized and therefore cannot be generalized to other populations. The adolescent girls under study could also be significantly different from a group of adolescent females of the same age, but who seek reproductive care at a pediatric office or a primary care facility where parental involvement in reproductive healthcare decisions may be higher. Additionally, the clinic under study was located in an urban area; adolescents in this area may be significantly different than those visiting clinics in rural and suburban areas.

\section{Conclusions}

This study provides insight into the complex phenomenon associated with adolescent girls' use of birth control. Contraceptive self-efficacy, the belief that girls can be sexually responsible in all situations, is influenced by demographic 
and medical variables, and is minimally influenced by social desirability. Further research is needed to determine if a shortened version of the CSS (without items 11 and 12) should be used. In all, continued study of CSE may greatly inform the way adolescent girls are educated about contraception and the CSS may eventually prove to be an effective tool within an intervention for reducing adolescent unintended pregnancy. 
Table 2

Demographic Characteristics Among 180 Adolescent Females Seeking Reproductive Health Care at a Local Family Planning Clinic

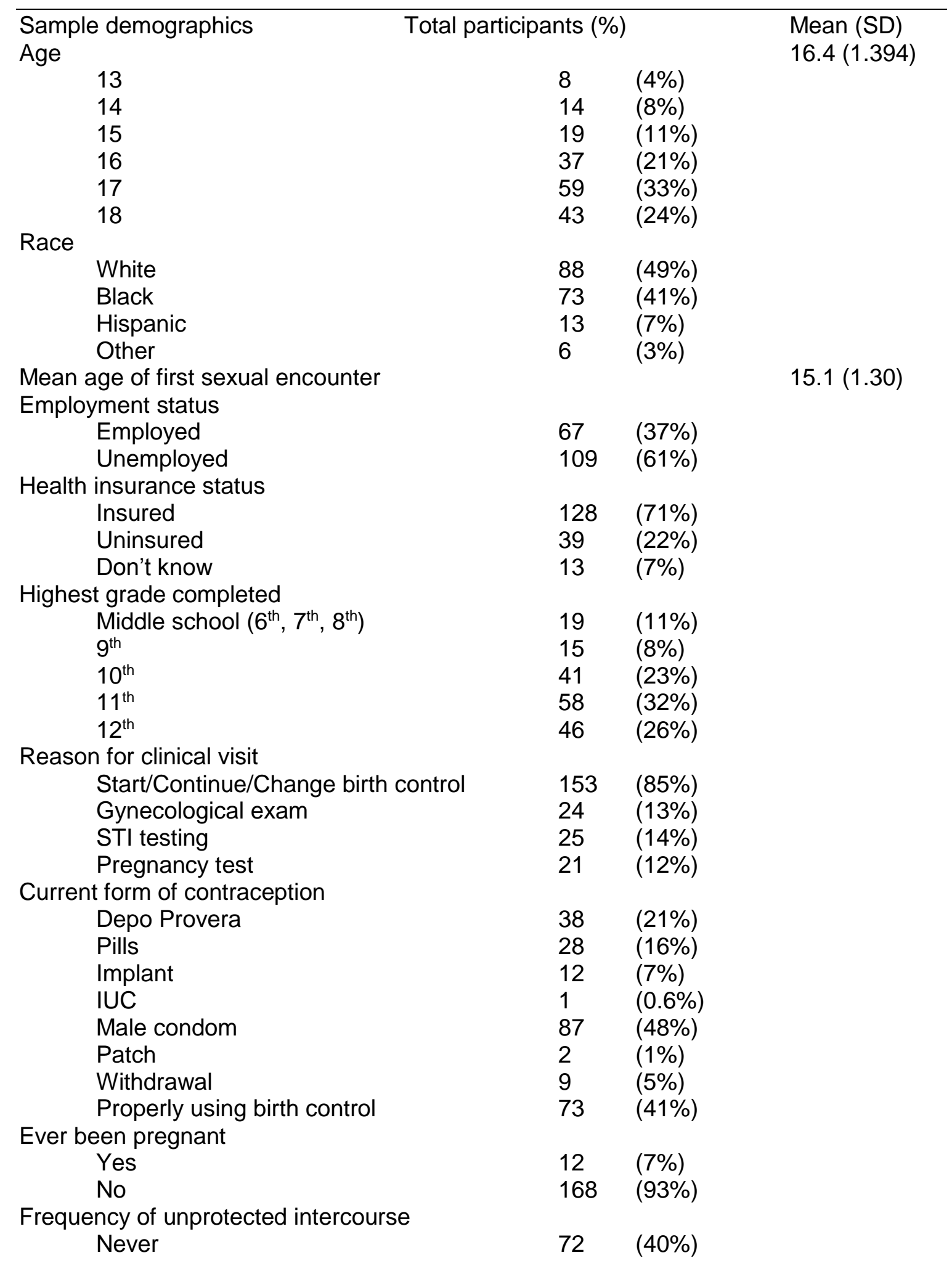


A couple of times

Several times

Many times

Always unprotected

$62 \quad(34 \%)$

$30 \quad(17 \%)$

$9 \quad(5 \%)$

$7 \quad(4 \%)$

Plans for Pregnancy

Never plans to get pregnant

$41 \quad(23 \%)$

5 years or more

4 years or less

$119 \quad(66 \%)$

$20 \quad(11 \%)$ 
Table 3

Factor Analysis of the Contraceptive Self-Efficacy Scale: Comparing Current Study Results to Levinson's (1986) Results

\begin{tabular}{|c|c|c|c|}
\hline Factor & Item loadings in current study & Items loadins & $g$ in Levinson \\
\hline 1 & $\begin{array}{ll}\# 13 b & (.999) \\
\# 13 d & (.449) \\
\# 13 c & (.438)\end{array}$ & $\begin{array}{l}\# 2 \\
\# 5 \\
\# 6 \\
\# 12 \\
\# 14 \\
\# 15\end{array}$ & $\begin{array}{l}(.637) \\
(.610) \\
(.539) \\
(.424) \\
(.592) \\
(.537)\end{array}$ \\
\hline 2 & $\begin{array}{ll}\# 7 & (.658) \\
\# 13 a & (.631) \\
\# 15 & (.613) \\
\# 4 & (.562) \\
\# 9 & (.549) \\
\# 1 & (.544)\end{array}$ & $\begin{array}{l}\# 1 \\
\# 13 a \\
\# 13 b \\
\# 13 c\end{array}$ & $\begin{array}{l}(.487) \\
(.695) \\
(.726) \\
(.729)\end{array}$ \\
\hline 3 & $\begin{array}{ll}\# 8 & (-.589) \\
\# 3 & (.564) \\
\# 10 & (.458)\end{array}$ & $\begin{array}{l}\# 4 \\
\# 7 \\
\# 13 d\end{array}$ & $\begin{array}{l}(.771) \\
(.717) \\
(.518)\end{array}$ \\
\hline 4 & $\begin{array}{ll}\# 2 & (.412) \\
\# 5 & (.409) \\
\# 6 & (.392) \\
\# 14 & (.383)\end{array}$ & $\begin{array}{l}\# 3 \\
\# 8 \\
\# 9 \\
\# 10 \\
\# 11\end{array}$ & $\begin{array}{l}(.733) \\
(-.429) \\
(.339) \\
(.438) \\
(.643)\end{array}$ \\
\hline Total & $\begin{array}{l}\text { explained } \\
50.4 \%\end{array}$ & $45.1 \%$ & \\
\hline
\end{tabular}


Table 4

Mean CSS Scores of 180 Adolescent Females Seeking Reproductive Health Care at a Local Family Planning Clinic

CSS item

Raw mean score (SD)

1. When I am with my boyfriend, I feel that I can

always be responsible for what happens

sexually with him.

2. Even if a boyfriend can talk about sex, I can't

tell a man how I really feel about sexual things.

3. When I have sex, I can enjoy it as something that I really wanted to do.

4. If my boyfriend and I are getting "turned on" sexually and I don't really want to have sexual intercourse (go-all-the-way, get-down), I can easily tell him no and mean it.

5. If my boyfriend didn't talk about the sex that was happening between us, I couldn't either.

6. When I think about what having sex means, I can't have sex so easily.

7. If my boyfriend and I are getting "turned on" sexually and I don't really want to have sexual intercourse, I can easily stop things so that we don't have intercourse.

8. There are times when l'd be so involved sexually or emotionally, that I could have sexual intercourse even if I weren't protected (using a form of birth control).

9. Sometimes I just go along with what my date wants to do sexually because I don't think I can take the hassle of trying to say what I want.

10. If there was a man (boyfriend) to whom I was very attracted physically and emotionally, I could feel comfortable telling him that I wanted to have sex with him.

11. I couldn't continue to use a birth control method if I thought my parents might find out.

12. It would be hard for me to go to the drugstore and ask for foam (Ovals, a diaphragm, a pill rx, etc) without feeling embarrassed.

13. If my boyfriend and I were getting really heavy into sex and moving towards intercourse and I wasn't protected...

a. I could easily ask him if he had protection

(or tell him that I didn't)

b. I could excuse myself to put in a diaphragm or foam (if I used them for birth control) 
c. I could tell him that I was on the pill or had an IUD (if I used them for birth control)

d. I could stop things before intercourse if I couldn't bring up the subject of protection.

14. There are times when I should talk to my boyfriend about using contraceptives; but, I can't seem to do it in the situation.

15. Sometimes I end up having sex with a boyfriend because I can't find a way to stop it.

Note: Asterisks $\left(^{*}\right)$ indicates item was reverse coded to calculate overall mean CSE score 


\section{Table 5}

Study Variables Correlated to CSE in Adolescent Females Seeking Reproductive Health Care at a Local Family Planning Clinic

\begin{tabular}{lll}
\hline Dependent Variable & Correlated Independent Variable & Pearson Correlation \\
CSE Mean Score & Age & $r=.306(p<.0001)$ \\
& Grade & $r=.295(p<.0001)$ \\
& Employment status & $r=.250(p<.0001)$ \\
& Partner knows participant & $r=.290(p<.0001)$ \\
& is using birth control & \\
Age at first sexual experience & $r=.204(p=.003)$ \\
Male condom use & $r=.178(p=.009)$ \\
& SDS-17 total score & $r=.177(p=.009)$ \\
&
\end{tabular}


Table 6

Mean Differences in CSS Scores among Adolescent Females Seeking Reproductive Health Care at a Local Family Planning Clinic

\begin{tabular}{|c|c|c|c|}
\hline \multicolumn{4}{|c|}{ Group Means (SD) } \\
\hline 13 & 3.40 (1.20) & $F=5.136$ & $p<.0001$ \\
\hline 14 & $3.77(.73)$ & & \\
\hline 15 & $4.12(.49)$ & & \\
\hline 16 & $3.90(.62)$ & & \\
\hline 17 & $4.25(.52)$ & & \\
\hline 18 & $4.24(.51)$ & & \\
\hline \multicolumn{4}{|l|}{ Race } \\
\hline White & $4.18(.62)$ & $F=2.834$ & $p=.040$ \\
\hline Black & $3.98(.64)$ & & \\
\hline Hispanic & $3.91(.63)$ & & \\
\hline Other & $4.52(.38)$ & & \\
\hline \multicolumn{4}{|l|}{ Grade } \\
\hline $6^{\text {th }}$ & $4.67(-)$ & $F=4.280$ & $\mathrm{p}<.0001$ \\
\hline $7^{\text {th }}$ & $3.32(.64)$ & & \\
\hline $8^{\text {th }}$ & $3.59(.98)$ & & \\
\hline $9^{\text {th }}$ & $3.90(.65)$ & & \\
\hline $10^{\text {th }}$ & $4.02(.60)$ & & \\
\hline $11^{\text {th }}$ & $4.27(.46)$ & & \\
\hline $12^{\text {th }}$ & $4.21(.56)$ & & \\
\hline \multicolumn{4}{|l|}{ Employment status } \\
\hline Employed & $4.29(.44)$ & $t=3.722$ & $\mathrm{p}<.0001$ \\
\hline Unemployed & $3.98(.68)$ & & \\
\hline \multicolumn{4}{|c|}{ Partner knows about birth control use } \\
\hline Yes & $4.43(.32)$ & $t=-5.72$ & $\mathrm{p}<.0001$ \\
\hline No & $3.99(.66)$ & & \\
\hline \multicolumn{4}{|c|}{ Sex frequency in the last month } \\
\hline $1 x$ or less & $4.05(.61)$ & $F=3.056$ & $\mathrm{p}=.030$ \\
\hline $2-3 x$ & $3.97(.73)$ & & \\
\hline $4-8 x$ & $4.38(.31)$ & & \\
\hline More than $8 x$ & $4.29(.52)$ & & \\
\hline \multicolumn{4}{|l|}{ Male condom use } \\
\hline Yes & $4.20(.64)$ & $t=-2.397$ & $p=.018$ \\
\hline No & $3.98(.60)$ & & \\
\hline \multicolumn{4}{|c|}{ Plans for pregnancy in the next... } \\
\hline 1 year & $4.31(.44)$ & $F=4.006$ & $p=.002$ \\
\hline 2 years & $3.95(.76)$ & & \\
\hline 3 years & $4.05(.87)$ & & \\
\hline 4 years & $3.70(.95)$ & & \\
\hline 5 or more years & $4.22(.48)$ & & \\
\hline Never & $3.77(.81)$ & & \\
\hline
\end{tabular}




\section{Table 7}

Predictors of Contraceptive Self-Efficacy in Adolescent Females Seeking Reproductive Health Care at a Local Family Planning Clinic

\begin{tabular}{lccc}
\hline \multicolumn{1}{c}{ Variable } & Unstandardized $B$ & Standardized $B$ & Sig \\
Age & .105 & .232 & $\mathrm{p}=.001$ \\
Partner's knowledge of participant & .363 & .241 & $\mathrm{p}=.001$ \\
birth control use & & & \\
Plan for pregnancy in $>5$ years & .325 & .245 & $\mathrm{p}<.0001$ \\
\hline
\end{tabular}


Figure 1

Illustration of the contraceptive self-efficacy theoretical framework

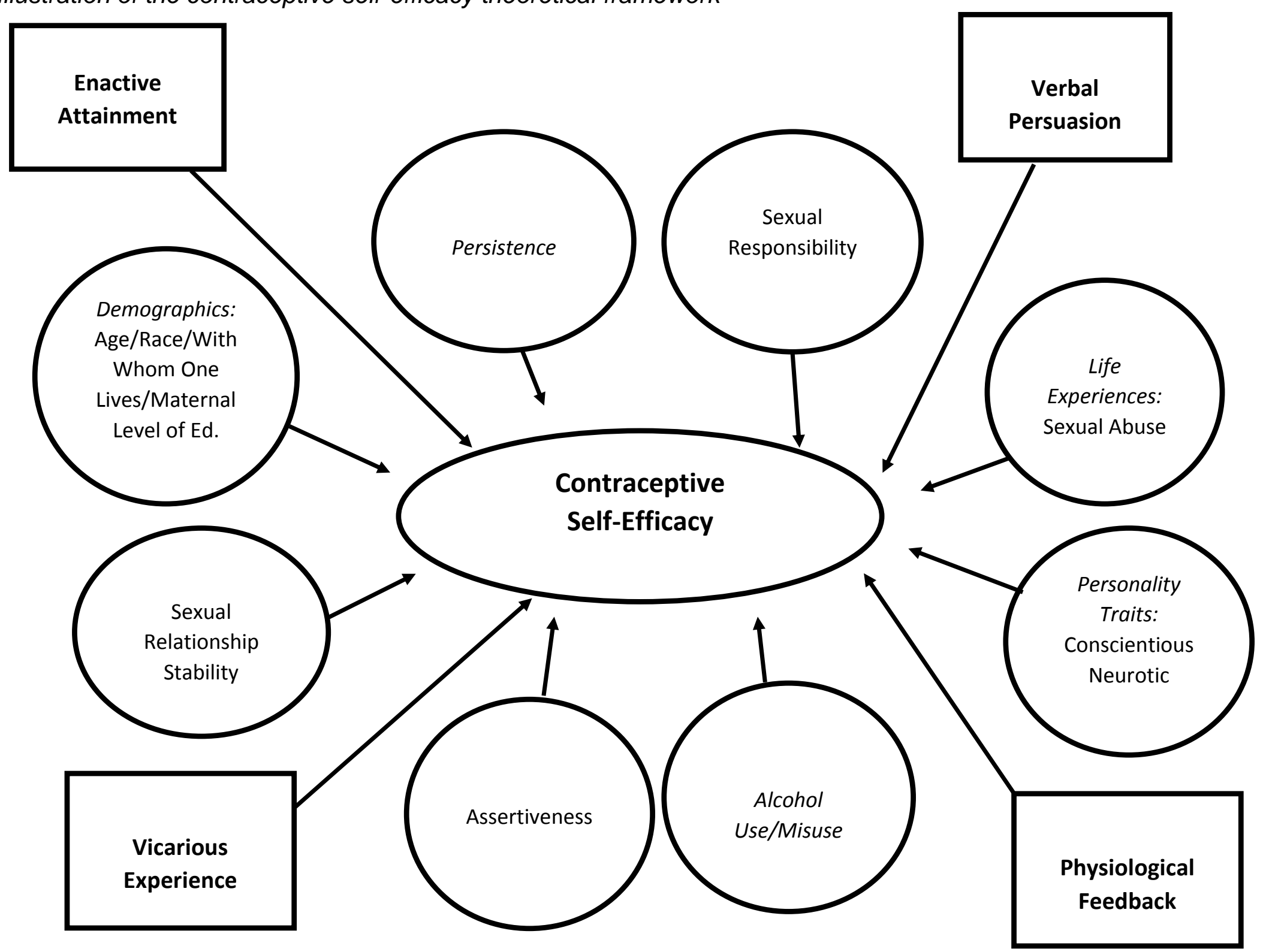




\section{CHAPTER IV}

\section{POSITIVE DEVIANTS IN FAMILY PLANNING: A QUALITATIVE STUDY}

Unintended pregnancy has been, and remains, a sensitive issue in the United States. By definition, unintended pregnancy encompasses all pregnancies the mother reports as mistimed or unwanted (USDHHS, 2012). Almost half of all pregnancies were unintended in the United States during 2006, those carried to term resulted in $\$ 11$ billion in public cost for routine prenatal care, labor and delivery, postpartum care and one year of infant care (USDHHS, 2012). One of the family planning goals proposed in Healthy People 2020 is to "improve pregnancy planning and spacing and prevent unintended pregnancy" (USDHHS, 2012). The ability to plan pregnancy has been shown to improve health outcomes for infants, children, women and families overall (CDC, 1999).

The phenomenon of unintended pregnancy occurs among women of all incomes, ages, and education levels (USDHHS, 2012). Women with the highest rates of unintended pregnancy are those between ages $18-24$, cohabiting with a male partner, earning income below the federal poverty line, having less than high school education, and are black or Hispanic (Finer \& Henshaw, 2006). Beyond the financial burden on society, unintended pregnancies carried to term have been associated with negative personal health and economic consequences. These negative effects include an increased risk for maternal 
depression, delays in initiating prenatal care, a reduced likelihood of breastfeeding, and an increased risk of physical violence during pregnancy (Cheng, Schwarz, Douglas et al., 2009; D’Angelo, Gilbert, Rochat, Santelli, \& Herold, 2004; Kost, Landry, \& Darroch, 1998; Logan, Holcombe, Manlove, \& Ryan, 2007).

The consequences of unplanned pregnancy also extend to the health of the child, with higher frequencies of birth defects and lower birth weights (CDC, 2006). As they age, these children are more likely to experience physical and mental health issues, have lower educational attainment and more behavioral issues in their teen years (Logan, Holcombe, Manlove, \& Ryan, 2007).

Across the United States, a large number of high school students are sexually active. The Youth Risk Behavior Surveillance survey performed by the Centers for Disease Control and Prevention (CDC) in 2012 found that nationally, $47.4 \%$ of high school students have had sex (CDC, 2012); an increase from $46 \%$ reported in the 2009 survey (CDC, 2009). Although the percentage of sexually active students that reported using a condom during their last sexual encounter increased between 1991-2003 (46.2\%-63\%), a slight decrease was noted from 2003 to 2011 (63\% to $61.1 \%$ ), and an even greater decrease was identified in 2012 to $60.2 \%$. This propensity for non-use of contraception among American teens appears complex, and has not yet been fully explored in research. It is imperative that healthcare providers in the United States work strategically to prevent unintended teenage pregnancies through a better understanding of the influences on contraceptive decision-making within this population. 


\section{Positive Deviance among Adolescent Contraceptive Users}

The concept of positive deviance is based upon the observation that in most settings, a few individuals follow uncommon practices that allow them to experience better consequences than their counterparts who share similar risks (Marsh, Schroeder, Dearden, Sternin, \& Sternin, 2004). Positive deviance was operationalized by Sternin in 1996 (Sternin, Sternin, \& Marsh, 1996). Positive deviants are viewed as focused, persistent and optimistic in the pursuit of their goals and are not thrown off course by the first sign of a setback. These characteristics, when combined with uncommon practices, make positive deviants more successful overcoming obstacles than their peers (Bloch, 2001). Positive deviants have been explored in efforts to improve malnutrition in over 40 countries, decrease genital mutilation in Egypt, reduce the trafficking of females in Indonesia, decrease MRSA hospital infections, improve hand hygiene among medical professionals, decrease hospital acquired infections, increase physical activity among rural adults and prevent HIV and Hepatitis C transmission in intravenous drug users (Friedman, Mateu-Gelabert, Sandoval, Hagan, \& Des Jarlais, 2008; Kegler, Alcantara, Dubruiel, Veluswany, Appelbaum, \& Handwerk, 2013; Lapping, Marsh, Rosenbaum, Swedberg, Sternin, Sternin, \& Schroeder, 2002; Lewis, 2009; Marra, Guastelli, deAraujo, dos Santos, Lamblet, Silva, et al., 2010; Marsh, Schroeder, Dearden, Sternin, \& Sternin, 2004;Spreitzer \& Sonenshein, 2004; Sternin \& Choo, 2000; Sternin, Sternin, \& Marsh, 1996). Individuals must meet three requirements to be considered a positive deviant: 1) the behavior being evaluated must be intentional and voluntary; not occurring 
due to force or coercion 2) the behavior should involve a departure from the norms of the group being referenced; it should not be an expected or consistent behavior for those in the group, and 3) the behavior must be considered honorable and praiseworthy (or noteworthy) across cultures, meaning it leads to positive outcomes worthy of recognition (Spreitzer \& Sonenshein, 2004).

Extending this concept to the current study, a positive deviant was identified as a sexually active adolescent girl who has been successful in using any method of contraception consistently. Consistency was defined as contraceptive use that is frequent enough to prevent unintended pregnancy for the previous year. Applying the aforementioned criteria for the positive deviance model, the examined behavior (consistent contraceptive use) is one that is intentional and voluntary, is a departure from the norm of risky adolescent sexual behavior, and is noteworthy in that it allows this group to prevent unintended pregnancy.

Identifying positive deviants in relation to reproductive health could have a positive impact on contraceptive use among adolescents. Identification of characteristics within this group may form the basis on which strategies for promoting consistent contraceptive use among adolescents can be built. Motive profiles, one's varying motivations to act in specific situations, are more accurate predictors of behavior and future achievement than psychometric testing and evidence derived only from an individual's history (Bloch, 2001). Considering this, the current study identified positive deviants and qualitatively explored their 
characteristics, perception and motivation to become and remain successful contraceptive users.

The purpose of this study was to identify characteristics of adolescent girls (13-18 years old) who are successful contraceptive users (positive deviants). The following research questions were explored:

a) What are the characteristics of positive deviants that make them successful contraceptive users?

b) How do adolescent females deal with external influences to become positive deviants?

\section{Methods}

\section{Sample}

From September to December, 2014, adolescent females were recruited from an urban family planning clinic in a southern U.S. city as part of a larger study. Adolescents were eligible to participate if they were 1) female, 2) between ages $13-18,3$ ) seeking reproductive health services at the clinic under study, 4) ever sexually active with a male partner, 5) able to read and understand English, and 6) reporting one year of successful contraceptive use. Participant medical records were examined for evidence of at least one year of a birth control prescription as well as no evidence of a positive pregnancy test in the last year. Study procedures were approved by the institutional review board of a southern university and the national research office associated with the clinic. 


\section{Procedures}

Clinical staff at the family planning clinic (Medical Assistants and Licensed Practical Nurses) and patient service specialists screened patients against the eligibility criteria using the clinic's medical history form to recruit study participants. Adolescents meeting the eligibility criteria were invited by clinical staff to meet privately with the primary investigator prior to their scheduled clinic appointment. In this meeting, the investigator explained study objectives and estimated length of the interview. If the patient expressed interest, eligibility was confirmed via medical record review, and informed consent was obtained. Interviews were conducted at the time of the participant's clinic visit.

Interviews were audio-recorded and transcribed verbatim by a trained research transcriptionist. Data collection and analysis occurred concurrently as multiple participants were recruited into the study. Data collection ceased when thematic saturation was reached.

The semi-structured interview guide was designed for the study to identify the ways in which female adolescents navigated external influences to become and remain successful contraceptive users. Literature was explored to identify variables found to be associated with contraceptive use and sexual activity in adolescent females as a foundation for development of the study instrument. A 26-question interview guide was developed using the following categorical domains (areas of focus) to reflect those areas identified in the literature as impacting contraceptive use: contraceptive self-efficacy, gender roles, media influence, motivation to use contraception, parental influence, peer influence, 
religion, sex education received at school and sexual pressure (Biglan, Noell, Ochs, Smolkowski, \& Metzler, 1995; Bruckner, Martin, \& Bearman, 2004; Epstein \& War, 2008; Gage, 1998; Kinsman, Romer, Furstenberg, \& Schwarz, 1998; Kirby, 2000; Levinson, 1986; Luster \& Small, 1994; Manlove, Terry-Humen, Ikramullah, \& Moore, 2006).

\section{Analysis}

Grounded theory, an analytical methodology linked with data collection using a systematically applied set of methods to generate an inductive theory or framework explaining a process or action (Glaser, 1992), was chosen to analyze the data. The audiotapes of each interview were transcribed verbatim by an independent professional transcriptionist. Transcripts from each interview were read by the investigator while listening to the audio recording to ensure the accuracy of transcription. The transcripts were analyzed with the assistance of Dedoose; a secure, web-based platform used to analyze qualitative and mixed methods research data in text, spreadsheet, photo, audio, and video formats (DeDoose, 2014). After ensuring accuracy, each transcript was reread and initial codes and impressions were documented (Glaser, 1978). Once initial codes were created, the data set was analyzed sentence by sentence until themes and theoretical ideas began to emerge. The line-by-line analysis identified major concepts and categories in the data across all transcripts. These concepts and categories were detailed and described, and the data was organized into them (Glaser, 1978). Themes were then compared across each interview to identify similarities and differences. This process was audited by one co-investigator 
who is an expert in qualitative research methodology, to ensure trustworthiness and to assure fidelity in the representation of the findings.

\section{Results}

\section{Sample}

Ten female adolescents participated in the study, completing one inperson interview. The sample was predominantly white, employed, insured, with an average age of 17 and had completed the $11^{\text {th }}$ grade. Majority of the patients seeking services at the clinic under study earned income below the federal poverty line (PPINK, 2016). Full details of the demographics for the study population may be found in Table 8. None of the adolescent females who were asked to participate chose to decline.

Multiple themes emerged from the analysis suggesting characteristics of positive deviants. Additional themes emerged describing the way in which adolescents dealt with external influences to become and remain positive deviants. When quoting participants, they are identified only by their age and chosen method of birth control.

\section{Themes}

\section{Research Question \#1: What are the characteristics of positive deviants that make them successful birth control users?}

Throughout the interviews, each participant expressed a fear of pregnancy, noting that if she became pregnant at a young age, her life would be negatively impacted in some capacity (her future, body, and relationship with her parents). When asked what helped her use birth control correctly, one participant 
expressed, "The thought of having a kid just terrifies me because, plus, I'm like, very small. So, I feel like it'd be really hard for me to be pregnant. So, yeah, having kids scares me to death. That's why every night at 8:00 o'clock l'm like, well, time to take the pill." (15-year-old pill user)

There was an articulated focus on being responsible among participants. Each participant noted an acceptance of her sexuality which included a commitment to consistent contraceptive use to prevent unintended pregnancy. When asked how her family's thoughts about teen sex and birth control use influenced what one participant did, she responded, “Yeah, they don't, their, yeah, their view is like I consider it and stuff but, at the end of the day, I'm going to do what I want, you know. I'm just going to be smart about it like they said. Just make sure l'm not, you know, doing anything stupid." (16-year-old pill user)

Responsibility for sexual decisions did not come without obstacles for positive deviants. Persistence in remaining responsible in using contraception was a common sub-theme among participants under the being responsible theme. Some discussed difficulties they had to overcome getting to the clinic while others discussed overcoming opposition from parents, peers and side effects from their chosen birth control method. When asked how parental opposition to birth control use affected what she did, one participant responded, "It makes me really sneaky. I don't want them (parents) to know at all costs."(18year-old contraceptive injection user) When asked about experiences using birth control, one participant responded, "Everything has been good. I mean, occasionally there's like six and seven days at a time where l'll be spotting or 
something and that kind of gets irritating considering that I haven't seen no blood in almost three years. So, for the past month or two, l've been spotting here and there. So, yeah, that's kind of making me angry but, besides that, everything's been okay." (16-year-old implant user) When asked to describe experiences using birth control, another participant responded, "A little stomach sickness with the shot. But they say that's like, mine only usually lasts for like a day...Maybe two...It's just like stomach feels a little nauseous every once in a while throughout the day. Not like throw up nauseous but just kind of like queasy. But not enough to make me not use it."(18-year-old contraceptive injection user)

All participants displayed assertiveness in the interview discussions, particularly when describing their interactions with their sexual partners. When asked to describe a time when she had to negotiate or discuss birth control use with a male partner, one participant responded, "Not too long ago, actually. It was a couple of months after I got this put in my arm and the guy I was messing with then and he like wanted to get me pregnant and I was just like, 'I'm not going for it' and he was just kind of like, 'well, if you don't let me get you pregnant, I'm going to stop messing with you' and I was just like, 'okay. I'm cool with it. Like, bye.' (16-year-old implant user)

Another consistent theme encompassed goals that participants have for the future. Each participant articulated the use of persistence, assertiveness and personal responsibility to protect their educational and career goals. Several participants had specific plans and noted that they were motivated not to get pregnant in order to protect them. When asked about the motivation not to get 
pregnant before she was ready, one participant responded, "Oh, yeah. I'm applying for spring courses for beauty school. Then, after I get that license, I'm going to eight more years of business management and business law school, first community college for two years and then transferring over to a university for the next six. I want to own my own salon but I want to know everything about it which is why l'm doing business management and law...."(18-year-old contraceptive injection user) Another participant responded, "Because my friend, she got pregnant and she has a baby girl and her and her boyfriend break up and she's like left on her own and her parents, they're not really good parents. And she doesn't have like a lot of money...I don't want to struggle and I want to give everything that I have to my little girl or boy when I get older." (15-year-old contraceptive injection user)

Each adolescent described being self-governing or autonomous in making decisions about using contraception. When asked how peers influenced her decision to use birth control, one participant noted that a friend at school was a positive influence on her contraceptive decision-making and was the reason she obtained contraception. She continued, "So, I went and got the shot same day, came home, told my mom. I'm like, "I'm on birth control." She's like, "What'd you get?" I'm like, "A shot." She's like, "Okay." (18-year-old contraceptive injection user) When asked the same question, another participant responded, "I just kind of do my own thing" (17-year-old contraceptive injection user)

In addition to these themes, participants described social support that played a role in their decision to access and continue contraception. Each 
participant discussed adults in her life who supported her decision to use birth control. The relationships with these adults included biological parents, stepparents, grandparents, parents of sexual partners, and cousins. When asked how her parents felt about teen sexual activity, one participant responded, "Well, they don't necessarily approve, but, at the same time, my parents are like, realistic. They're like, we don't necessarily want you doing it or anything but, like, they also know that I'm a teenager and they know how teenagers are because like my dad and mom said, you know, they were teenagers once. So, they'd rather me be protected and everything from having a kid than just going behind their back and doing it." (17-year-old contraceptive injection user)

Additionally, each participant discussed peers who supported and encouraged her decision to use birth control. Often, study participants who were first-time users heard about birth control from a friend. When asked to describe the first time she heard about birth control and who that information came from, one participant responded, "From my friend. She was talking about how she was on Depo and that I should be on it because she didn't want me to get pregnant. And I was like, "oh, okay, what is that?" And she was like, "yeah, the Depo shot, you only got to get it...every three months." (17-year-old-contraceptive injection user) When asked to describe conversations she's had with her friends about birth control, one participant responded, "Well, a whole lot of my friends have babies already. So, that was one of the main things. I was just not trying to end up like them. So, a couple of my friends pushed me towards the direction of, 
yeah, you should get birth control because having kids isn't such a fun thing at such a young age."(16-year-old implant user)

\section{Research Question \#2: How do adolescent females deal with external influences to become positive deviants?}

Adolescent females navigate external pressures in several ways to become and remain successful contraceptive users, and thus, positive deviants. Participants discussed their participation in religious activities with their families, but were not aware of any influence of these activities and beliefs on their sexual or contraceptive decisions. When asked to describe ways that her family's religion influenced her personal views on birth control, one participant responded, “It doesn't really, to be honest. We're Christian. We go to church every, every week if not every few weeks or so. We try to go as much as we can but we're not like, Bible thumpers, I guess, you could call it. I mean, that's why I'm even on the pill. If we were like real old-fashioned and stuff, my grandma wouldn't even put me on the pill because she'd be like, you shouldn't be doing it anyway. So, it doesn't really affect it at all." (16-year-old pill user)

Study participants discussed media influences from multiple perspectives. Some reported hearing negative things about birth control in the media, particularly regarding side effects. When asked what she had seen in the media about birth control, one participant responded, "The pills, I mostly see birth control pills on TV; not too much, if anything, else. Actually, the commercials are pretty bad about birth control pills. They talk about it causing cancer and all kinds of other things." (17-year-old contraceptive injection user) When asked 
about things on social media related to birth control, one participant responded, "Sometimes girls talk about, I think it's the Depo shot, or something that, I mean, some girls don't like taking it because it makes them fat..." (16-year-old implant user)

Several participants described the mainstream media as sexualized and encouraging teens to engage in sex and other risky behaviors. When asked what she sees in the media about birth control, one participant responded, "I honestly don't, like, hardly see anything, I feel like it's not advertised as much because like on TV, I see them shows, like "16 and pregnant," and, to me, that's like saying it's okay for a teenager to be irresponsible, and get pregnant. I feel like that is like telling kids it's okay and they're thinking, well, if I get pregnant at 16, I might be able to become, like, famous." (17-year-old contraceptive injection user) Regardless of media messaging that seemingly supports sexual irresponsibility, when asked how the media influences her birth control decisions, one participant responded, "It makes me want to get on birth control. It just reiterates the fact that it's something that I probably need to do." (18-year-old pill user)

Experiences with sex education was a domain that varied across participants. The comprehensiveness of in-school sex education varied. Most participants perceived the sex education they received at school as lacking, illtimed and unrealistic. When asked to describe the sex education she received in school, one participant responded, "I feel like that was a big issue. The only time they talked about it was in 9th grade during health class and I feel like that wasn't 
enough and I think people should be informed like what sex is, how to have safe sex and just birth control. There's all different aspects, instead of them having to go find stuff about it or just doing it without any protection." (18-year-old pill user)

Several participants suggested a more comprehensive approach to sex education for students between the eighth and ninth grades. At this time, they believed that sex education would be more valuable and of more interest to students. When asked when sex education should be taught in school, one participant responded, "High school. So, around my age. 14, 15, 16 somewhere around there it should be introduced, if not already introduced...I think 7 th to 8 th graders nowadays should be introduced to it because most kids that are in 7th or 8th grade have those older brothers and older sisters that have already been doing this and they probably already know more than they should." (16-year-old implant user) Another participant responded, "I don't remember a whole lot about it. Like I know in the books and stuff there were like, I guess, it said some things like told you how you could practice safe sex and everything but I don't remember a whole lot about it. But I feel like I would remember it more if it would have been in high school instead of middle school though." (17-year-old contraceptive injection user) Other participants noted that the sex education they received at school was comprehensive and that there was nothing they would have added to the course.

Each participant was asked about gender roles, to describe what it means to be a "good girl" and how this expectation from society influenced how she dealt with boys. The definition of a "good girl" was consistent across participants. 
When asked what it meant to be a "good girl," one participant responded, "As a good girl, okay. You know, like reserved and sweet and just good. Like they don't get in trouble. They do their school work and stuff like that. And they don't really talk to a lot of boys and stuff like that." (16-year-old pill user) Another participant responded, "I have a few good girls. I know a few. They're mostly popular...They're very outgoing. They're into people. You don't see them with like, it's a serious boyfriend but, at the same time, they're waiting and most of the good girls I know get everything done in school. Like they are preparing for their future." (17-year-old contraceptive injection user)

However, variation existed across participants on whether or not they felt societal pressure to be a "good girl." Some participants expressed that society pressures them to be a "good girl." When asked whether there was more pressure to be a "good girl" or "bad girl," one participant responded, "I think there's more pressure on me, personally, to be a good girl because everybody wants me to get good grades. Everybody wants me to be with a good guy. Everybody just wants to see me be successful." (18-year-old contraceptive injection user)

Other participants said that the societal pressure they feel is to be a "bad girl," which they defined as behaviors such as being sexually promiscuous, consuming drugs/alcohol, and wearing revealing clothing. Responding to the same question, another participant responded, “I don’t really see people saying, well, you should abstain from sex or you shouldn't go out and party. I feel like everybody's saying, you should have sex. You should have a boyfriend and, if 
you don't have that, then, you're not really in with everybody. So, yeah, definitely media and just your social crowd has a lot to do with that. People don't want you to be a good girl." (18-year-old pill user)

During the interviews, participants were asked to imagine themselves in a situation where a sexual partner attempted to pressure them to have unprotected sex or get pregnant before they were ready. Most participants shared that they would directly communicate with their sexual partner that they were unwilling to comply. One participant responded, "I wouldn't. Straight up, if I don't want to, ain't gonna happen. Like, I'm sorry. Like, that ain't my problem. Like, I don't want to have sex. If I'm not feeling good, I'm not having sex. If I don't like feel it, I'm not having sex. Like, if I don't want to, it's not gonna happen. I shouldn't be forced to do something I don't want to do and I'm not going to." (18-year-old contraceptive injection user) Another participant responded, "If I didn't want to have sex with my boyfriend, he would be like kind of like grumpy...so, that's when I gotta go like love, like l'm not like sexually l'd just like hug him and stuff. Like, I'm so sorry and stuff like that. Sometimes, he understands...but sometimes I lie." (16-year-old contraceptive injection user)

Two participants reported that even if they did not want to have sex at that time, they would consent if their partner was persistent. One participant responded, "I think I would go ahead and just do that because, I mean, if he really wants to, I'm not going to sit there, I mean, I could say no if I really didn't want to and he would be okay with that but I, I don't know. This kind of goes back to the religion kind of thing in a weird way. Like submit to your spouse and 
like your body is not your own any more. That's kind of my viewpoint on it." (18year-old pill user)

\section{Discussion}

This research provides insight into the characteristics and contextual navigation strategies of positive deviants. Adolescent females who are consistent users of contraception had multiple characteristics that supported the targeted behavior. They prioritize being sexually safe and responsible, are persistent, are able to access birth control despite obstacles and are not deterred by side effects of their chosen birth control method. Positive deviants are highly motivated to use birth control by vicarious experiences and interactions with peers and trusted adults. They stay focused on and protect the goals they have for their futures and maintain autonomy in sexual and contraceptive decision-making. Lastly, positive deviants are enabled by social support (peers and trusted adults). A theoretical model of these relationships is depicted in Figure 2.

Domains documented in the literature as influencing risky sexual behaviors were discussed with each participant. The results from the current study support some findings from previous research. Research suggests that parenting styles and the parent-child relationship influence adolescent risky sexual behaviors (Baumeister, Flores, \& Marin, 1995; Capaldi, Crosby, \& Stoolmiller, 1996; Huebner \& Howell, 2003; Ito, Gizlice, Owen, Foust, Leone, \& Miller, 2006; Jaccard, Dodge, \& Dittus, 2003; Luster \& Small, 1994; McNeely, Shew, Beuhring, Sieving, Miller, \& Blum, 2002; Miller, Decker, McCauley, Tancredi, Levenson, Waldman, et al., 2010). Parenting styles were not the focus 
of the reported study, however, participant narratives described being "close to" or having a "good relationship with" an adult guardian (parent, step-parent, partner's family, grandparent). As such, this literature was supported by study findings. Parent-child communication about sexual risk-taking has also been found to influence adolescent's sexual decision-making and consistent contraceptive use (Huebner \& Howell, 2003; Luster \& Small, 1994; McNeely, Shew, Beuhring, et al., 2002). This finding was also supported by the current study. Each participant noted a trusted adult (parent, step-parent, partner's family member, grandparent) with whom they were able to have open dialogue about sex and birth control. Further, research in this domain has noted that parental values against adolescent intercourse decrease the risk of teen pregnancy as evidenced by girls remaining sexually abstinent, postponing intercourse, having fewer partners or using contraceptives consistently (Jaccard, Dodge, \& Dittus, 2003). This literature was supported in the sense that each participant reported their parents as disapproving of them being sexually active, but supportive of their birth control use if they were aware.

Several studies have found that adolescents are more likely to use contraception if they think that is what their peers are doing (Brown, Trevino, Richard, Brown, Bell, \& Montoya, 2004; Epstein \& War, 2008; Harper, Calegari, Raine, Blum, \& Darney, 2004; Kinsman, Romer, Furstenberg, \& Schwarz, 1998). The results of this study support the importance of peers on a girl's decision to use birth control. Each participant discussed openness with her peers about 
birth control and many discussed ways in which her peers encouraged her to obtain birth control.

The literature associated with adolescent contraception notes that religion influences adolescent sexual behavior. Previous studies report that adolescents who report higher levels of religiosity and frequency of church attendance are less likely to engage in sexual intercourse (Griffin, Lesser, Uman, \& Nyamathi, 2003; Manlove, Terry-Humen, Ikramullah, \& Moore, 2006; Regnerus, 2005). Prior research also identified that adolescents who are more involved with religion and religious activities have later sexual debut when compared to others (Manlove, Terry-Humen, Ikramullah, \& Moore, 2006; Regnerus, 2005). This literature was neither supported nor refuted in the reported study. While few participants reported consistent church attendance, none noted any religious influence on their sexual or contraceptive behaviors.

Previous research suggests that messages in the media influence teen's sexual behavior and decisions about whether or not to use contraception (Collins, Martino, Elliott, \& Miu, 2006; Epstein \& War, 2008; L'Engle, Brown, \& Kenneavy, 2006; Nonoyama, Tsurugi, Shirai, Ishikawa, \& Horiguchi, 2005; Ward, 2002). This study partially supports the literature in this area. Each participant noted the presence of messages encouraging sex and sexual irresponsibility in the media and negativity toward birth control, particularly highlighting its potential side effects. However, each positive deviant made the independent decision to obtain and consistently use birth control. 
Studies have noted that the effects of abstinence-only programs diminish over time and that there is no significant impact on delaying the onset of sexual intercourse (Kirby, 2000; Kohler, Manhart, \& Lafferty, 2008). Comprehensive sex education programs however, have been shown to delay the onset of intercourse, reduce the frequency of intercourse, decrease the number of sexual partners, and increase condom or other contraceptive use, therefore reducing sexual risk-taking behaviors for lengthy periods of time (Kirby, 2000). Participants in this study had varying levels of sex education but had suggestions on ways to provide teens with the information that they need to be sexually responsible. These positive deviants suggested a comprehensive and realistic approach to sex education that was introduced during either the $8^{\text {th }}$ or $9^{\text {th }}$ grade.

The literature suggests that gender roles within a given community may impact social expectations for males and females. These expectations have been found to influence the way that adolescent females deal with members of the opposite sex, especially in sexual situations (Blanc, 2001; Browning, Hatfield, Kessler, \& Levine, 2000; Dodoo \& Tempenis, 2002; Gage, 1998; Lucke, 1998; Pearson, 2006; Varga, 2003). It has been reported that gender power distributions manifest in sexual situations (Blanc, 2001; Dodoo \& Tempenis, 2002; Pearson, 2006). For example, in cultures where women are expected to be docile and less expressive of their needs, this behavior extends to the sexual act and can cause women to engage in risky sexual behaviors without speaking up for themselves (Lucke, 1998; Pearson, 2006; Varga, 2003). However, this literature was not fully supported in the current study. Although two participants 
noted that at times they believe they should "submit to their partner" sexually, the others were assertive with their partners, refusing the sexual act if they were not in the mood or adequately protected. The same assertion was noted in the discussion of birth control and the importance of being responsible with sexual partners.

Previous research has also demonstrated that young women may be coerced or pressured into engaging in sexual behaviors whether they are protected or unprotected (Biglan, Noell, Ochs, Smolkowski, \& Metzler,1995; Brown, Trevino, Richard, Brown, Bell, \& Montoya, 2004; Gamuko, Moneyham, Enah, \& Childs, 2012; Williams, Brett, \& Abma, 2003). This coercion may range from peer pressure from a sexual partner to the use of negative emotional behavior, like anger and arguing, to physical force (Biglan, Noell, Ochs, Smolkowski, \& Metzler,1995; Gamuko, Moneyham, Enah, \& Childs, 2012; Williams, Brett, \& Abma, 2003). The majority of the study participants reported being assertive with their sexual partners, clearly being willing to refuse sex when it was unwanted. As previously noted, two participants indicated that they would engage in consensual sex if their partners expressed a desire to have sex even if she was not in the mood.

Studies have indicated that some adolescent girls are motivated by their plans for future success, while others are motivated by wishing to avoid sexually transmitted infections or a fear of their parents' response to an unplanned pregnancy (Bruckner, Martin, \& Bearman, 2004; Cooper, Agocha, \& Powers, 1999; Ryan, Franzetta, \& Manlove, 2007). Additionally, some adolescent girls 
are motivated not to use contraception because of access issues and stories of side effects they have heard from others (Ryan, Franzetta, \& Manlove, 2007; Stevens-Simon, Kelly, Singer, \& Cox, 1996). The current study results support this body of literature. Although few reported a fear of their parent's response to an unplanned pregnancy, each participant noted that her future goals were her motivation to prevent unintended pregnancy.

\section{Implications}

The reported study not only adds to the literature about this important health issue, the results of this study also have implications for research, practice and policy. Further exploration is needed into the characteristics of positive deviants described in this study, but within larger and more diverse samples. It may be helpful to measure the effects that these characteristics have on the contraceptive use of adolescent females. Further research is needed to explore the impact of gender roles and social expectations on the contraceptive use and sexual responsibility of adolescent females. A study such as this could inform an intervention designed to teach relevant skills to adolescent females and also encourage the characteristics found to be consistent among the positive deviants studied. Additionally, it may be of interest to explore the influence of using positive deviants as peer educators on the retention and application of information taught in sex education classes.

Clinically, study results highlight the importance of identifying potential obstacles for adolescents related to their contraceptive use and discussing plans to navigate them. Such planning could empower adolescents with the skill and 
savvy to meet these obstacles and navigate them successfully. It may also be important for clinicians to discuss and nurture conversations surrounding the adolescent female's goals for the future. Discussing the importance of achieving future goals, as found in the study, could encourage adolescents to be consistently sexually responsible.

The policy implications from this study encompass in-school sex education. The study participants highlight the need for a comprehensive and practical approach to sex education. The appropriate timing of sex education was also discussed in this study. Both suggestions can be mandated by local and/or state legislation and may be of interest to both advocates and policymakers.

Although study findings further illuminate the perspectives of an important population, this study is not without limitations. This non-random sample was collected from one urban family planning clinic, and could be significantly different from a population of adolescent females of the same age, but seeking reproductive health care at a school-based clinic, a pediatric office, or primary care facility. The sample could also vary significantly from similar adolescents in a rural or suburban setting. Additionally, there were no 13 or 14 -year-old girls in the study and their responses could have varied significantly from the 15-18 year olds represented here. Lastly, when discussing religion, participants were asked about their awareness of any influence of religion on their reproductive health practices; in previous studies, religiosity scales were used, therefore, it is difficult to compare the results from this study to the aforementioned studies. 


\section{Conclusions}

Study findings suggest that adolescent females who are positive deviants have consistent characteristics that may influence their success in using contraception. Further research is needed in this area to determine the effect that each characteristic has on adolescent contraceptive use. Interventions that aim to nurture these characteristics among adolescent females may be successful in increasing consistent contraceptive use among this population, which may positively impact their unintended pregnancy rate. 
Table 8

Demographic Characteristics Among 10 Positive Deviants Seeking Reproductive Health Care at a Local Family Planning Clinic

\begin{tabular}{|c|c|c|}
\hline Demographic variable & Total participants $(n=10)$ & Mean (SD) \\
\hline \multicolumn{3}{|l|}{ Age } \\
\hline 15 & 1 & \\
\hline 16 & 2 & \\
\hline 17 & 3 & \\
\hline 18 & 4 & \\
\hline \multicolumn{3}{|l|}{ Race } \\
\hline White & 7 & \\
\hline Black & 3 & \\
\hline Mean Age of First Sexual Encounter & & $15.1(1.30)$ \\
\hline \multicolumn{3}{|l|}{ Employment Status } \\
\hline Employed & 6 & \\
\hline Unemployed & 4 & \\
\hline \multicolumn{3}{|l|}{ Health Insurance Status } \\
\hline Insured & 6 & \\
\hline Uninsured & 3 & \\
\hline Don't Know & 1 & \\
\hline \multicolumn{3}{|l|}{ Highest Grade Completed } \\
\hline $8^{\text {th }}$ & 1 & \\
\hline $9^{\text {th }}$ & - & \\
\hline $10^{\text {th }}$ & 1 & \\
\hline $11^{\text {th }}$ & 4 & \\
\hline $12^{\text {th }}$ & 4 & \\
\hline \multicolumn{3}{|l|}{ Reason for clinical visit } \\
\hline Continue birth control & 8 & \\
\hline Gynecological exam & 1 & \\
\hline STI testing & 1 & \\
\hline \multicolumn{3}{|l|}{ Current form of contraception } \\
\hline Depo Provera & 6 & \\
\hline Pills & 3 & \\
\hline Implant & 1 & \\
\hline \multicolumn{3}{|l|}{ Plans for pregnancy } \\
\hline 5 years or more & 8 & \\
\hline 3 years & 2 & \\
\hline
\end{tabular}


Figure 2

Model of Positive Deviant Characteristics Encouraging Consistent Adolescent Contraceptive Use

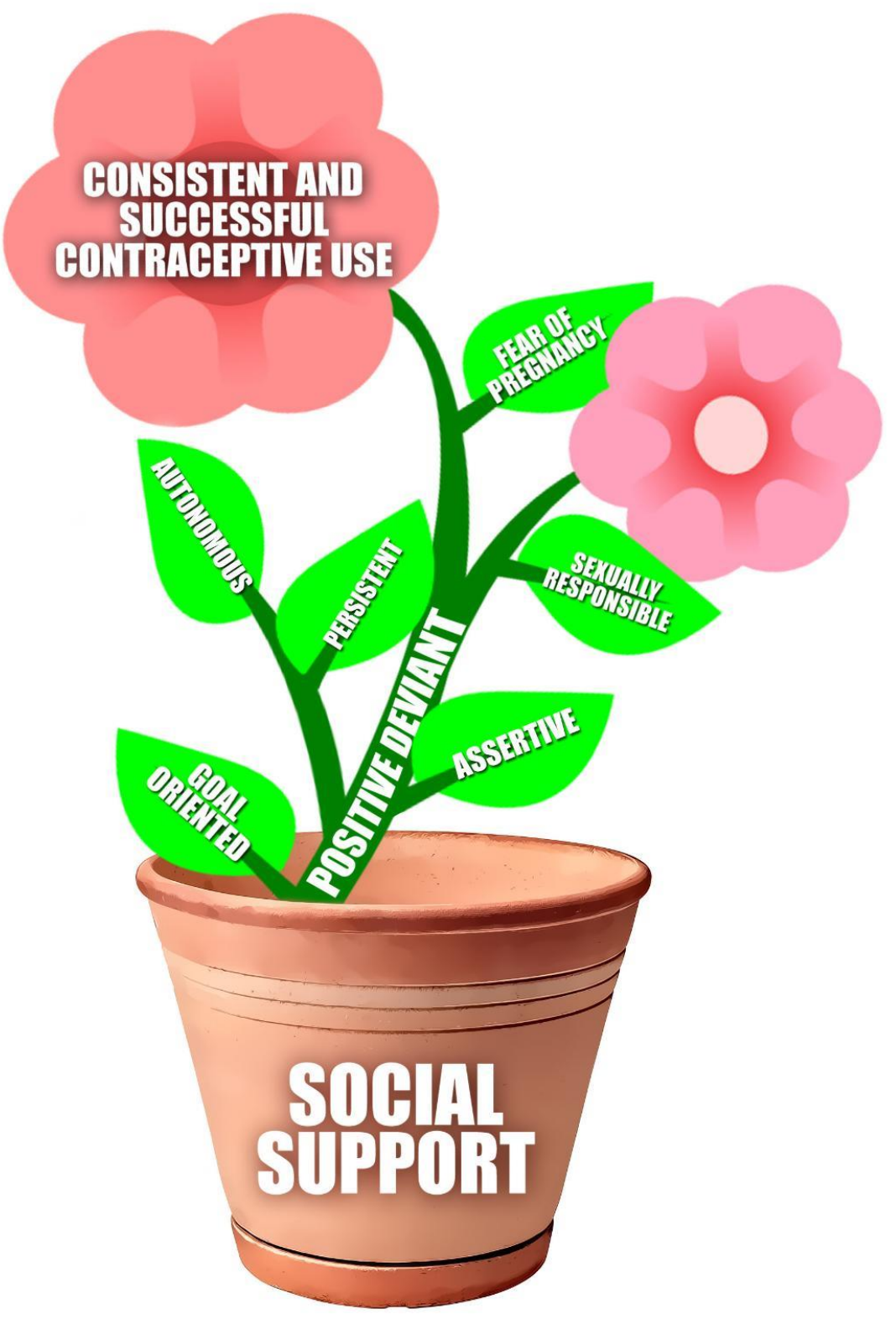




\section{CHAPTER V}

\section{DISCUSSION AND CONCLUSIONS}

The overall purposes of this dissertation were to explore factors that contribute to successful contraceptive use among adolescent females (ages 1318) seeking reproductive health services at a local family planning clinic and to explore the psychometric properties and the most comprehensive use of the Contraceptive Self-Efficacy Scale (CSS) among the same population. The specific aims of this study, as well as their associated research questions are as follows:

1. Explore factors that influence contraceptive self-efficacy (CSE) in adolescent females.

a) What is the CSE of adolescent females seeking reproductive health services at an urban family planning clinic?

b) How do medical and demographic variables influence CSE?

c) Does social desirability influence CSE?

d) What factors best predict CSE?

e) What group differences exist in the CSE of adolescent females seeking reproductive health services?

2. Evaluate the dimensionality and internal consistency reliability of the Contraceptive Self-Efficacy Scale (CSS) in adolescent females seeking reproductive health services. 
a) What are the psychometric qualities of the CSS in adolescent females seeking reproductive health services?

b) What factor structure best fits the CSS in adolescent females seeking reproductive health services?

3. Identify characteristics of adolescent girls who are successful contraceptive users (positive deviants).

a) What are the characteristics of adolescent girls who are successful contraceptive users?

b) What similarities/differences are there across successful contraceptive users?

c) How do adolescent females deal with external influences to become positive deviants?

\section{Synthesis of Findings}

\section{Characteristics Influencing CSE}

Several demographic variables were found to influence CSE in adolescent females. These variables include age, race, highest grade completed and employment status. This finding supports previous literature reporting that age, race, level of education and employment status influence CSE (Aitken, 2003; Heinrich, 1993; Hovsepian et al., 2010; Longmore et al., 2003; Magoun Moreno, 2000). The variables that were newly revealed in this study to influence CSE were an adolescent girl's sexual partner's knowledge of contraceptive use, age at first sexual experience, male condom use, social desirability and future plans for pregnancy. These variables require further exploration. 
Chapter Four also highlights several characteristics that are shared by positive deviants. These characteristics included persistence, autonomy and assertiveness. Positive deviants were persistent in being responsible birth control users; this included accessing birth control despite obstacles (parental disapproval of teen sex or birth control use, etc.) and side effects of their chosen contraceptive method. They each portrayed autonomy in their ability to make independent decisions about birth control and taking responsibility for their sexual activity. Additionally, social norms and the perceived expectation from one's social circle to be a "good girl" or a "bad girl" were discussed in Chapter Four. This discussion revealed autonomy as a consistent personality trait among positive deviants. Although positive deviants were able to recognize societal norms and peer pressures, they opted to make their own decisions and not be influenced by societal norms. Lastly, assertiveness when communicating with sexual partners about birth control was a consistent characteristic. Positive deviants reported being able to stop sex if it was unwanted, but may struggle stopping sex in an emotionally charged situation. Although this last finding appears contradictory, it was confirmed in the data presented both in Chapter Three and Chapter Four.

\section{Social Support and Influences}

In chapters Three and Four it is revealed that the social network of adolescent females can influence their contraceptive self-efficacy and contraceptive use. The adults in an adolescent girl's life (parents, grandparents, adult relatives, parents of sexual partners, etc.) and whether or not they support 
the girls' contraceptive decisions may impact her pursuit of contraception and influence the type of contraception she selects. Beyond this, adolescents often consider the contraceptive method side effects and negative consequences reported by a trusted adult in their own decision-making processes. Peer relationships are also important in contraceptive use and contraceptive selfefficacy among adolescent females. Peers are often the first people from whom adolescent females hear about birth control. The experience of an adolescent girl's peers using birth control, whether good or bad, is strongly considered when making their own birth control decisions. Although the influence of peers was greatly discussed in the qualitative interviews reported in Chapter Four, there was only a minimal relationship noted in Chapter Three between social desirability and CSE.

\section{Sex Education in Schools}

In Chapter Four, interview participants were asked about the sex education they received in school. These responses revealed that a comprehensive approach to sex education including complete information about birth control, condom negotiation skills and assertiveness techniques introduced in the $8^{\text {th }}$ or $9^{\text {th }}$ grade may be the most helpful in providing students with the information they need to be sexually responsible. This suggestion is in alignment with literature stating that adolescents participating in comprehensive sex education have later sexual commencement and use contraception more often (Kirby, 2000). Considering the influence of peers mentioned previously, it may 
be beneficial for positive deviants to teach or assist in teaching their peers about these sensitive topics.

\section{Plans for the Future}

Girls who have a plan for their future are more sexually responsible. This future plan refers to the timing of future pregnancies as well as future academic or career plans as demonstrated in Chapters Three and Four. In Chapter Three, girls who planned to experience pregnancy in one year and girls who planned to experience pregnancy in five or more years had the highest raw CSE mean scores. The positive deviants interviewed in Chapter Four explained that the desire to achieve their future goals was a big factor in their decision to take action toward delaying pregnancy. These findings suggest that girls who have created a plan for their future careers or have plans regarding when they want to become pregnant are more likely to consistently use birth control as a way to protect those plans. In several interviews, positive deviants revealed that they wanted to defer pregnancy until they were financially stable because they had seen a parent or peer struggle financially due to an early or unintended pregnancy. These findings provide further insight into the impact of social influences on adolescent girls and their decisions to use birth control as well as to the importance of goal-setting and life planning among this population.

\section{Measuring CSE}

The results from Chapter Three support Levinson, Wan and Beamer's assertion (1998) that the CSS (Levinson, 1986) is a reliable instrument for measuring contraceptive self-efficacy. Also in alignment with Levinson, Wan and 
Beamer (1998), a four factor structure was found to be the best fit for the CSS. However, it should be considered that items 11 and 12 on the instrument could be problematic due to their poor loading on any factor. Cronbach's alpha, as previously stated, would not significantly decrease if either of these items were removed from the instrument. Also supporting Levinson, Wan and Beamer (1998), Chapter Three reveals that using the total CSS score to evaluate CSE while also examining each item score as an individual variable is the most comprehensive way to examine CSE.

\section{Evaluation of the Connection Between the Theory and Measurement of CSE}

While the CSS has been reported as a reliable instrument for the measurement of CSE, this study presents questions about its comprehensiveness. When examining the items on the CSS as well as its four factors, there are no consistent connections between what is being measured and the four external resources of self-efficacy theory as described in detail by Bandura (1977) (enactive attainment, vicarious experience, verbal persuasion, physiological feedback) upon which the entire notion of contraceptive selfefficacy is based (Levinson, 1986). As previously noted in this dissertation, CSS items are behavioral in nature and intend to measure how much an adolescent girl believes she can or would exercise control in sexual situations to prevent pregnancy, if that is what she desires. As such, the scale items appear to be measuring internal resources associated with successful contraceptive use such as autonomy, assertiveness, being sexually responsible, and persistence. Each of these resources were found in Chapter 4 to be consistent characteristics of positive deviants, and are thus important when evaluating and predicting 
successful adolescent contraceptive use. However, it is important that a theoretically-based instrument also includes items associated with the foundational constructs of that theory. This dissertation demonstrates that both internal and external influences impact contraceptive use among adolescent females, therefore any instrument aimed at identifying successful contraceptive users should measure aspects of both of these influences. Thus, it is recommended that the CSS be altered to include questions measuring each of the four external resources of self-efficacy theory. These additional items could be created using qualitative research data such as the data reported in Chapter

4 , so that the items authentically reflect the voices of effective contraceptive users. Altering the CSS in this way may increase the percentage of variance in contraceptive use that the overall instrument is able to explain, and make it more useful to both researchers and clinicians.

\section{Implications}

The results from Chapters Two, Three and Four demonstrate the importance of research on contraceptive self-efficacy and positive deviants in the realm of reproductive health. Beyond the knowledge this study adds to the literature on adolescent contraceptive use, it has research, practice and public policy implications.

\section{Research}

This dissertation presents the need for future research on this topic. One of the demographic variables requiring further exploration is employment status; in particular, what makes girls who are employed more likely to use contraception 
more consistently than their unemployed counterparts? This is a research question that is best suited for a qualitative inquiry. As previously noted, girls who report planning a pregnancy in one year and those planning a pregnancy in five or more years have similarly high CSE scores suggesting they are more consistent contraceptive users than those with other pregnancy plans. This assertion requires further quantitative and qualitative inquiry to explore the similarities between these two groups. It may also be of interest to explore social norms and their influence on adolescent girl's reproductive health decisions. Beyond this, the effect of positive deviance on contraceptive self-efficacy should be further explored, possibly in focus group settings, to add more depth to the findings reported in Chapter Four.

The CSS should be explored with the removal of items 11 and 12 to determine if the instrument should be altered prior to future use. Additionally, further instrument development is necessary to ensure that the CSS measures the main constructs of self-efficacy theory. Lastly, and again considering the impact noted in this study of peers on adolescent females, future research is needed to explore the benefit of using positive deviants as peer educators to facilitate sex education programming.

\section{Practice}

The results from this dissertation can inform contraceptive counseling and the formulation of evidence-based sex and contraceptive education programming. Health care providers should consider including in their contraceptive counseling a discussion of adolescent girls' goals for the future 
while encouraging them that their decision to consistently use contraception now can help protect their future goals. Additionally, health care providers are encouraged to help adolescents plan for obstacles they may face while using contraception including side effects and discussing contraceptive use with their sexual partners. This may help increase the percentage of adolescents who are using birth control consistently from the current $41 \%$ discussed in Chapter Three. This finding also supports the use of long-acting reversible contraceptives such as intrauterine devices and implants. The use of more long term methods of birth control may improve consistent contraceptive use and provide protection for adolescents if they find themselves in emotionally aroused situations in which they do not feel comfortable bringing up the topic of birth control. Last, use of the CSS is encouraged in clinical settings to help health care providers identify individual risk factors and areas for further education or skill building for adolescents seeking contraception.

\section{Public Policy}

Chapter Four reveals a suggestion by positive deviants for a comprehensive sex education program for all students that is introduced in the $8^{\text {th }}$ or $9^{\text {th }}$ grades. As Kirby (2000) found, comprehensive approaches to sex education are more likely to help adolescents prevent unintended pregnancy. Considering this, it may be of interest to legislative bodies and reproductive health advocacy groups to pursue comprehensive sex-education mandates so that all students are getting the same, medically accurate information and negotiation skills they need to be sexually responsible. 


\section{Summary}

This dissertation demonstrates the importance of continued exploration

into adolescent contraceptive use; it is a complex topic that is influenced by many variables. Contraceptive self-efficacy is an important variable influencing the use of birth control among adolescent females and as the strongest predictor of contraceptive use, requires more exploration to better equip both health professionals and adolescents alike. Demographic variables influence CSE, but there are other characteristics like assertiveness, responsibility and educational and career planning that may be taught to and nurtured within adolescent girls to increase their CSE and in turn increase contraceptive use. Although the Contraceptive Self-Efficacy Scale provides insight into the variation in contraceptive use, further research is needed to explore other variables that influence CSE. Examining variables such as pregnancy planning and employment status can add depth to the literature regarding adolescent contraceptive decision-making. Use of the CSS (Levinson, 1986) is recommended in the exploration of CSE examining the total score and individual item scores to get a comprehensive picture of CSE in the population under study or for the individual in a clinical setting. However, the exploration of the item deletions suggested is highly recommended. In all, this dissertation suggests that continued research in this area is important and could reveal the reproductive health information and life skills necessary to inform clinical practice, improve contraceptive use, and prevent unintended pregnancy in female adolescents. 


\section{REFERENCES}

Aitken, K. L. (2003). Do aspects of personality determine sexually responsible behavior and contraceptive self-efficacy among adolescent females (Unpublished master's thesis)? University of Canterbury, Christchurch, New Zealand.

American Civil Liberties Union of Kentucky. (2013). JCPS Current State of Sexual Education. Retrieved from http://www.scribd.com/doc/271651771/JCPS-Current-State-of-SexualEducation-2013

Arbuckle, J. L. (2013). IBM SPSS Amos 22 User's Guide. Retrieved from ftp://public.dhe.ibm.com/software/analytics/spss/documentation/amos/22.0 /en/Manuals/IBM_SPSS_Amos_User_Guide.pdf

Bandura, A. (1977). Self-efficacy: Toward a unifying theory of behavior change. Psychological Review, 84(2), 191-215.

Bandura, A. (1982). Self-efficacy mechanism in human agency. American Psychologist, 37(2), 122-147.

Bandura, A. (1986). The explanatory and predictive scope of self-efficacy theory. Journal of Social and Clinical Psychology, 4(3), 359-373.

Bandura, A. (1989). Regulation of cognitive processes through perceived selfefficacy. Developmental Psychology, 25(5), 729-735.

Bandura, A. (1997). Self-Efficacy: The exercise of control. New York: W.H. 


\section{Freeman.}

Bandura, A. (2000). Exercise of human agency through collective efficacy. Current Directions in Psychological Science, 9(3), 75-78.

Baumeister, L.M., Flores, E., \& Marin, B.V. (1995). Sex information given to Latina adolescents by parents. Health Education Research, 10(2), 233241.

Biglan, A., Noell, J., Ochs, L., Smolkowski, K., \& Metzler, C. (1995). Does sexual coercion play a role in the high-risk sexual behavior of adolescent and young adult women? Journal of Behavioral Medicine, 18(6), 549-568.

Bilodeau, A., Forget, G., \& Tetreault, J. (1994). L'auto-efficacite relative a la contraception chez les adolescents: La validation de la version francaise de l'echelle de mesure de Levinson [Contraceptive self-efficacy in adolescents: Validation of the French version of Levinson's scale]. Canadian Journal of Public Health, 85, 115-120.

Blanc, A.K. 2001. The effect of power in sexual relationships on sexual and reproductive health. Studies in Family Planning, 32(3): 189-213.

Bloch, S. (2001). Positive deviants and their power on transformational leadership. Journal of Change Management, 1(3), 273-279.

Brown, V.L., Trevino, R., Richard, A., Brown, H., Bell, D.C., \& Montoya, I. (2004). An analysis of peer influence and peer selection on human immunodeficiency virus risk behaviors. Journal of Applied Biobehavioral Research, 9(3), 137-155.

Browning, J.R., Hatfield, E., Kessler, D., Levine, T. (2000). Sexual motives, 
gender, and sexual behavior. Archives of Sexual Behavior, 29(2), 135153.

Bruckner, H., Martin, A., \& Bearman, P. S. (2004). Ambivalence and pregnancy: Adolescents' attitudes, contraceptive use and pregnancy. Perspectives on Sexual and Reproductive Health, 36(6), 248-257.

Capaldi, D., Crosby, L., \& Stoolmiller, M. (1996). Predicting the timing of first sexual intercourse for at-risk adolescent males. Child Development, 67, 344-359.

Centers for Disease Control and Prevention. Achievements in public health (1999). Family planning. 48(47):1073-80. Retrieved from http://www.cdc.gov/mmwr/preview/mmwrhtml/mm4847a1.htm

Centers for Disease Control and Prevention, Agency for Toxic Substances and Disease Registry. (2006). Recommendations to improve preconception health and health care-United States: A report of the CDC/ATSDR Preconception Care Work Group and the Select Panel on Preconception Care. Atlanta: CDC.

Centers for Disease Control and Prevention. (2009). Contraceptive use among postpartum women - 12 states and New York City, 2004-2006. MMWR. Morbidity and Mortality Weekly Report, 58(30), 821-6.

Centers for Disease Control (2009). Youth Risk Behavior Surveillance. Retrieved from http://www.cdc.gov/mmwr/preview/mmwrhtml/ss6104a1.htm Centers for Disease Control (2012). Youth Risk Behavior Surveillance. Retrieved from http://www.cdc.gov/mmwr/pdf/ss/ss6104.pdf 
Centers for Disease Control and Prevention (2015). Kentucky - 2015 State Health Profile. Retrieved from http://www.cdc.gov/nchhstp/stateprofiles/pdf/kentucky profile.pdf

Cheng D, Schwarz E, Douglas E, et al. (2009). Unintended pregnancy and associated maternal preconception, prenatal and postpartum behaviors. Contraception, 79(3), 194-8. doi:10.1016/j.contraception.2008.09.009

Collins, R., Martino, S.C., Elliott, M., \& Miu, A. (2006). Relationships between adolescent sexual outcomes and exposure to sex in media: Robustness to propensity-based analysis. Developmental Psychology, 47(2), 585-591.

Committee on Adolescents. (2007). Contraception and Adolescents. Pediatrics, 120(5), 1135-1148. doi: 10.1542/peds.2007-2535

Cooper, M.L., Agocha, V.B., \& Powers, A.M. (1999). Motivations for condom use: Do pregnancy prevention goals undermine disease prevention among heterosexual young adults? Health Psychology, 18(5), 464-474.

Cox, J. \& Lambert, J. (2013). Microsoft Access 2013: Step by Step. Retrieved from http://misprivate.boun.edu.tr/kutlu/bis515/access2013.pdf

Crowne, D.P. \& Marlowe, D. (1960). A new scale of social desirability independent of psychopathology. Journal of Consulting Psychology, 24, 349-354.

Crowne, D.P. \& Marlowe, D. (1964). The approval motive: Studies in evaluative dependence. New York: Wiley.

D’Angelo D, Gilbert BC, Rochat R, Santelli, J, \& Herold, J.M. (2004). Differences between mistimed and unwanted pregnancies among women who have 
live births. Perspectives on Sex and Reproductive Health, 36(5), 192-7. doi:10.1363/3619204

Dedoose (2014). About us. Retrieved from http://www.dedoose.com/about-us/

Dodoo, F. \& Tempenis, M. (2002). Gender, power, and reproduction: Rural-

Urban differences in the relationship between fertility goals and contraceptive use in Kenya. Rural Sociology, 67(1), 46-70.

Edwards, A.L. (1957). The social desirability variable in personality assessment and research. New York: The Dryden Press.

Epstein, M. \& Ward, L.M. (2008). Always use protection: Communication boys receive about sex from parents, peers and the media. Journal of Youth Adolescence, 37, 113-126. doi: 10.1007/s10964-007-9187-1

Finer, L. \& Henshaw, S. (2006). Disparities in rates of unintended pregnancy in the United States, 1994 and 2001. Perspectives on Sexual and Reproductive Health. 38(2):90-6. doi: 10.1363/3809006

Friedman, S.R., Mateu-Gelabert, P., Sandoval, M., Hagan, H., \& Des Jarlais, D. (2008). Positive deviance control-case life history: A method to develop grounded hypotheses about successful long-term avoidance of infection. BCM Public Health, 94(8),1-10. doi:10.1186/1471-2458-8-94

Gage, A. (1998). Sexual activity and contraceptive use: The components of the decision making process. Studies in Family Planning, 29(2): 154-166. doi: $10.2307 / 172156$

Gamuko, C.A., Moneyham, L., Enah, C. \& Childs, G. (2012). The moderating effect of sexual pressure on young urban women's condom use. Research 
in Nursing and Health, 35, 4-14. doi: 10.1002/nur.20465

Glaser, B. (1978). Advances in the methodology of grounded theory: Theoretical sensitivity. Mill Valley, CA: Sociology Press.

Glaser, B. (1992). Basics of grounded theory analysis. Mill Valley, CA: Sociology Press.

Glaser, B \& Strauss, A. (1967). The discovery of grounded theory. Chicago: Aldine Publishing Company.

Griffin, D., Lesser, J., Uman, G., \& Nyamathi, A. (2003). Teen pregnancy, motherhood, and unprotected sexual activity. Research in Nursing and Health, 26(1), 4-19. doi: 10.1002/nur.10062

Guttmacher Institute. (2016). Unintended Pregnancy in the United States.

Retrieved from https://www.guttmacher.org/pubs/FB-Unintended-

Pregnancy-US.html?gclid=Cj0KEQiA3t-2BRCKivi-

suDY24gBEiQAX1wiXMic_Owgvj9SDJDzZ93ZmabAsVm6mC8T014Yaxh XvV4aAq908P8HAQ

Harper, C., Calegari, L., Raine, T., Blum, M., \& Darney, P. (2004). Adolescent clinic visits for contraception: Support from mothers, male partners and friends. Perspectives on Sexual and Reproductive Health, 36(1), 20-26. doi: $10.1363 / 3602004$

Heinrich, L.B. (1993). Contraceptive self-efficacy in college women. Journal of Adolescent Health, 14, 29-276.

Hovsepian, S. L., Blais, M., Manseau, H., Otis, J., Girard, M.E. (2010). Prior victimization and sexual and contraceptive self-efficacy among adolescent 
females under protective services care. Health Education and Behavior, 37(1), 65-83. doi:10.1177/10901981008327730

Huebner, A.J., \& Howell, L.W. (2003). Examining the relationship between adolescent risk-taking and perceptions of monitoring, communication and parenting styles. Journal of Adolescent Health, 33, 71-78.

Ip, W., Sin, L.Y., \& Chan, D. (2009). Contraceptive self-efficacy and contraceptive knowledge of Hong Kong Chinese women with unplanned pregnancy. Journal of Clinical Nursing, 18, 2416-2425.

doi: 10.1111/j.1365-2702.2009.02829.x

Ito, K.E., Gizlice, Z., OwenO’Dowd, J., Foust, E., Leone, P.A., \& Miller, W. C. (2006). Parent opinion of sexuality education in a state with mandated abstinence education: Does policy match parental preference? Journal of Adolescent Health, 39, 634-641. doi: 10.1016/j.jadohealth.2006.04.022

Jaccard, J., \& Dittus, P. J. (2000). Adolescent perceptions of maternal approval of birth control and sexual risk behavior. American Journal of Public Health, 90(9), 1426-1430.

Jaccard, J., Dodge, T., \& Dittus, P. (2003). Do adolescents want to avoid pregnancy? Attitudes toward pregnancy as predictors of pregnancy. Journal of Adolescent Health, 33, 79-83.

Kearney, M.S. \& Levine, P.B. (2012). Why is the birth rate in the United States so high and why does it matter? National Bureau of Economic Research. Retrieved from http://www.nber.org/papers/w17965

Kegler, M.C., Alcantara, I., Dubruiel, N., Veluswany, J.K., Appelbaum, H., \& 
Handwerk, S. (2013). Positive deviants: A qualitative study of physically active adults in rural environments. Journal of Primary Prevention, 34, 5-

15. doi: $10.1007 / \mathrm{s} 10935-013-0291-6$

Kinsman, S.B., Romer, D., Furstenberg, F., \& Schwarz, D. (1998). Early sexual initiation: The role of peer norms. Pediatrics, 102(5), 1185-1192.

Kirby, D. (2000). What does the research say about sexuality education? Educational Leadership, October, 72-76.

Kohler, P.K., Manhart, L.E., \& Lafferty, W.E. (2008). Abstinence-only and comprehensive sex education and the initiation of sexual activity and teen pregnancy. Journal of Adolescent Health, 42, 344-351. Retrieved from https://www-clinicalkey-com.echo.louisville.edu/\#!/content/playContent/1$\underline{\text { s2.0-S1054139X07004260 }}$

Kost, K. \& Henshaw, S. (2014). U.S. Teenage Pregnancies, Births and Abortions, 2010: National and State Trends and Trends by Age, Race and Ethnicity, Retrieved from http://www.guttmacher.org/pubs/USTPtrends10.pdf

Kost K, Landry D, \& Darroch J. (1998). Predicting maternal behaviors during pregnancy: Does intention status matter? Family Planning Perspectives, 30(2), 79-88. Retrieved from http://www.jstor.org.echo.louisville.edu/stable/2991664?seq=1\#page scan $\underline{\operatorname{tab} c}$ ontents

Lapping, K., Marsh, D.R., Rosenbaum, J., Swedberg, E., Sternin, J., Sternin, M., \& Schroeder, D.G. (2002). The positive deviance approach: Challenges 
and opportunities for the future. Food Nutrition Bulletin, 23(1), 128-135.

L'Engle, L., Brown, J.D., \& Kenneavy, K. (2006). The mass media are an important context for adolescents' sexual behavior. Journal of Adolescent Health, 38(3), 186-192. doi:10.1016/j.jadohealth.2005.03.020

Levinson, R.A. (1984). Contraceptive self-efficacy: A primary prevention strategy. Journal of Social Work and Human Sexuality, 3(1), 1-15.

Levinson, R.A. (1986). Contraceptive self-efficacy: A perspective on teenage girls contraceptive behavior. Journal of Sex Research, 22(3), 347-369.

Retrieved from

http://www.jstor.org.echo.louisville.edu/stable/3812572?seq=1\#page scan tab contents

Levinson, R. A. (1995). Reproductive and contraceptive knowledge, contraceptive self-efficacy and contraceptive behavior among teenage women. Adolescence, 30(117), 65-85.

Levinson, R.A., Wan, C.K., \& Beamer, L.J. (1998). The contraceptive selfefficacy scale: Analysis in four samples. Journal of Youth \& Adolescence, 27, 773-793. Retrieved from http://link.springer.com.echo.louisville.edu/article/10.1023\%2FA\%3A10228 $\underline{65900} 546$

Lewis, J. (2009). Positive deviance: A case study in finding and harnessing the wisdom of organization communities. Business Information Review, 26(4), 282-287. doi: $10.1177 / 0266382109349643$

Logan C, Holcombe E, Manlove J, \& Ryan, S. (2007). The consequences of 
unintended childbearing: A white paper. Washington: Child Trends, Inc., Retrieved from http://www.childtrends.org/Files//Child Trends-

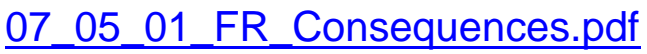

Longmore, M.A., Manning, W.D., Giordano, P.C., \& Rudolph, J.L. (2003).

Contraceptive self-efficacy: Does it influence adolescents' contraceptive use? Journal of Health and Social Behavior, 44(1), 45-60. Retrieved from http://www.jstor.org/stable/1519815

Lucke, J.C. (1998). Gender roles and sexual behavior among young women. Sex Roles, 39(4), 273-297. doi: 10.1023/A:1018806622585

Luster, T., \& Small, S.A. (1994). Factors associated with sexual risk-taking behaviors among adolescents. Journal of Marriage and the Family, 56, 622-632. doi: $10.2307 / 352873$

Magoun Moreno, A.M. (2000). The impact of security of attachment to mothers, and contraceptive self-efficacy upon female college students' contraceptive use (Doctoral dissertation). California School of Professional Psychology, Los Angeles, California.

Manlove, J., Terry-Humen, E., Ikramullah, E., \& Moore, K. (2006). The role of parent religiosity in teens' transitions to sex and contraception. Journal of Adolescent Health, 39(4), 578-587. doi:10.1016/j.jadohealth.2006.03.008

Marra, A., Guastelli, L.R., deAraujo, C.M., dos Santos, J.L., Lamblet, L.C., Silva, M., et al. (2010). Positive deviance: A new strategy for improving hand hygiene compliance. Infection Control and Hospital Epidemiology, 31(1), 12-20. doi: $10.1086 / 649224$ 
Marsh, D.R., Schroeder, D.G., Dearden, K.A., Sternin, J., \& Sternin, M. (2004).

The power of positive deviance. British Medical Journal, 329, 1177-1179.

Matteson, K.A., Peipert, J.F., Allsworth, J., Phipps, M.G, \& Redding, C.A. (2006).

Unplanned pregnancy: Does past experience influence the use of a contraceptive method? Obstetrics \& Gynecology, 107, 121-127.

doi: 10.1097/01.AOG.0000192170.16746.ea

McKay, A., \& Barrett, M. (2010). Trends in teen pregnancy rates from 1996-2006:

A comparison of Canada, Sweden, U.S.A., and England/Wales. Canadian Journal of Human Sexuality, 1/2 (43-52)

McNeely C, Shew ML, Beuhring T, Sieving R, Miller BC, Blum RW. (2002)

Mothers' influence on the timing of first sex among 14-and 15-year-olds.

Journal of Adolescent Health, 31(3):256-265. doi: 10.1016/S1054-

$139 \times(02) 00350-6$

Miller, E., Decker, M. R., McCauley, H. L., Tancredi, D. J., Levenson, R. R., Waldman, J.et al. (2010). Pregnancy coercion, intimate partner violence and unintended pregnancy. Contraception, 81, 316-322. Retrieved from https://www-clinicalkey-com.echo.louisville.edu/\#!/content/playContent/1s2.0-S0010782409005228

Nicoletti, A. (2004). Teen pregnancy prevention issues. Journal of Pediatric and Adolescent Gynecology, 17(2), 155-156. doi: 10.1016/j.jpag.2004.01.014

Nonoyama, M., Tsurugi, Y.,Shirai, C., Ishikawa, Y., \& Horiguchi, M. (2005). Influence of sex-related information for STD prevention. Journal of Adolescent Health, 36, 442-445. 
Paulhus, D.L. (2002). Socially desirable responding: The evolution of a construct. In H.I.Braun, D.N.Jackson, \& D.E.Wiley (Eds.), The Role of Constructs in Psychological and Educational Measurement (pp. 49-69). Mahwah, NJ: Lawrence Erlbaum.

Pearson, J. (2006). Personal control, self-efficacy in sexual negotiation, and contraceptive risk among adolescents: The role of gender. Sex Roles, 54, 615-625. doi: 10.1007/s11199-006-9028-9

Peshkin, F. (1991). Contraceptive self-efficacy in adolescents: A comparative study of male and female contraceptive behavior (Unpublished master's thesis). University of Illinois at Urbana-Champaign, Urbana, Illinois.

Planned Parenthood of Kentucky and Indiana. Annual Report. Retrieved from https://www.plannedparenthood.org/files/4014/4563/2426/Planned Parent hood_Annual_Report_2015.pdf

Plichta, S.B. \& Kelvin, E. (2013). Munro's Statistical Methods for Health Care Research. Philadelphia: Lippincott Williams \& Wilkins.

Regnerus, M. (2005). Talking about sex: Religion and patterns of parent-child communication about sex and contraception. The Sociological Quarterly, 46(1), 79-105. doi: 10.1111/j.1533-8525.2005.00005.x

Resnick, B. (2008). Theory of self-efficacy. In Smith, M.J. \& Liehr, P.R. (Eds.), Middle Range Theory for Nursing (pp. 183-204). New York: Springer Publishing Company.

Ryan, S., Franzetta, K., \& Manlove, J. (2007). Knowledge, perceptions, and motivations for contraception: Influence on teen's contraceptive 
consistency. Youth and Society, 39(2), 182-208.

doi: 10.1177/0044118X06296907

Santelli, J. S., Lindberg, L. D., Finer, L. B., Singh, S. (2007). Explaining recent declines in adolescent pregnancy in the United States: The contribution of abstinence and improved contraceptive use. American Journal of Public Health, 97(1), 150-156. doi: 10.2105/AJPH.2006.089169

Spreitzer, G.M. \& Sonenshein, S. (2004). Toward the construct definition of positive deviance. American Behavioral Scientist, 47(6), 828-847. doi: $10.1177 / 0002764203260212$

Sternin, J. \& Choo, R. (2000). The power of positive deviancy. Harvard Business Review, 1, 14-15.

Sternin, M., Sternin, J., \& Marsh, D. (1996). Rapid, sustained childhood malnutrition alleviation through a "positive deviance" approach in rural Vietnam: Preliminary findings. In E. Keeley, B. R. Burkhalter, O. Wollinka, N. Bashir (Eds.), The hearth nutrition model: Applications in Haiti, Vietnam, and Bangladesh, Report of a technical meeting at world relief corporation (19-21). Arlington, VA: World Relief Corporation.

Stevens-Simon, C., Kelly, L., Singer, D., \& Cox, A. (1996). Why pregnant adolescents say they did not use contraceptives prior to conception. Journal of Adolescent Health, 19(1), 48-53. doi:10.1016/1054-139X(95)00281-V

Stober, J. (1999). The social desirability scale: Development and first results on 
reliability and validity. Diagnostica, 45, 173-177.

Stober, J. (2001). The social desirability scale-17 (SDS-17). European Journal of Psychological Assessment, 17(3), 222-232.

Tran, U.S., Stieger, S. \& Voracek, M. (2012). Psychometric analysis of Stober's social desirability scale (SDS-17): An item response theory perspective. Psychological Reports, 111(3), 870-884.

doi: 10.2466/03.09.PR0.111.6.870-884

United States Department of Health and Human Services. (2011). Human research protection. Retrieved from http://answers.hhs.gov/ohrp/questions/7274

United States Department of Health and Human Services. (2012). Healthy people 2020: Adolescent health. Retrieved from http://www.healthypeople.gov/2020/topicsobjectives2020/overview.asp $x$ ?topicid $=2$

Van den Bossche, F., \& Rubinson, L. (1997). Contraceptive self-efficacy in adolescents: A comparative study of male and female contraceptive practices. Journal of Sex Education and Therapy, 22, (2), 23-29.

Varga, C.A. (2003). How gender roles influence sexual and reproductive health among South African adolescents. Studies in Family Planning, 34(3), 160172. doi: $10.1111 / \mathrm{j} .1728-4465.2003 .00160 . x$

Waltz, C. F., Strickland, O. L., \& Lenz, E. R. (2010). Measurement in Nursing and Health Research. New York: Springer Publishing Company.

Ward, L.M. (2002). Does television exposure affect emerging adults' attitudes 
and assumptions about sexual relationships? Correlational and experimental confirmation. Journal of Youth Adolescence, 31,1-15. doi: $10.1023 / \mathrm{A}: 1014068031532$

Wiggins, J.S. (1962). Definition of social desirability and acquiescence in personality inventories. In Messick, S. \& Ross, J. (Eds.), Measurement in personality and cognition. New York: John Wiley and Sons, Inc.

Williams, C. M., Brett, K. M., \& Abma, J. C. (2009). Coercive first intercourse and unintended first births. Violence and Victims, 24, 351-363.

Wright, C. (1992). Factors associated with contraceptive behavior among black college students. Unpublished doctoral dissertation, University of Oregon.

Yosha, A.M. (2008). Contraceptive self-efficacy among female adolescents (Unpublished master's thesis). University of Washington, Seattle, Washington. 


\section{CURRICULUM VITAE \\ Ashley Danielle Miller, WHNP-BC, PhD Candidate \\ PO Box 22923 \\ Louisville, KY 40252 \\ (502) 425-7659 (Office) \\ Ashley@AthenaHealthandWellness.com}

\section{Education}

1/2011- Present

UNIVERSITY OF LOUISVILLE

Louisville, Kentucky

$\mathrm{PhD}$ Program in Nursing

PhD Candidate as of 8/20/2013

1/2011- 05/2012

UNIVERSITY OF LOUISVILLE

Health Science Educator Teaching Certificate

06/2006- 08/2008

UNIVERSITY OF LOUISVILLE

Louisville, Kentucky

Masters of Science in Nursing

Women's Health Nurse Practitioner Track

09/2001-05/2005

BEREA COLLEGE

Berea, Kentucky

Bachelor of Science in Nursing

\section{Employment}

January 2015- Present

\section{Co-Owner, Nurse Practitioner}

Athena Health and Wellness: A Center for Women

-Well woman exams

-Problem GYN visits

-IUC/Implant insertions and removals

-Contraceptive management

-Pregnancy Testing

-Practice Marketing and Management

August 2008- April $2015 \quad$ Nurse Practitioner

Planned Parenthood of Kentucky and Indiana

-Well woman exams

-Problem GYN visits 
-IUC/Implant insertions and removals

-Contraceptive management

-Pregnancy Testing and Options counseling

-Accreditation, QA/RM and Cultural Competency Team

Member

-Clinical preceptor for NP and SANE students, and

Medical Residents

August 2010- July 2013 Quality Assurance/Risk Manager

Planned Parenthood of Kentucky and Indiana

-Internal Chart and Procedure Audits

-Monitor compliance with national medical standards and

guidelines

-Assess and manage affiliate risk

-Monitor clinical compliance (clinician competencies, licensure, etc.)

-National Patient Safety Committee member

-National Root Cause Analysis Committee member

August 2011-May 2012

Graduate Teaching Assistant

August 2007- May 2008

University of Louisville, School of Nursing

-Student/Professor Communication

-Proctor/grade exams

-Assist with teaching/clinical simulations

-Clinical instructor

May 2005-October $2007 \quad$ Registered Nurse

University of Louisville Hospital

Center Women and Infants

-Care for postpartum, antepartum and gynecologic patients

-Relief charge nurse duties

\section{National Board Certification(s) and state RN Licensure(s)}

Registered Nurse (RN)- Kentucky- 05/2005

Women's Health Nurse Practitioner- 08/2008

CPR Certified- 01/2004

\section{Professional Memberships and Activities}

Member, Sigma Theta Tau Honor Society of Nursing

Kentucky Coalition of Nurse Practitioners and Nurse Midwives

Member, Sigma Theta Tau Honor Society

Member, Phi Kappa Phi Honor Society

Member, Fleur de Lis Honor Society

Member, Mortar Board Honor Society 


\section{Honors and Awards}

2014 Glamour Magazine Phenomenal Woman of the Year- Kentucky

SIGS Diversity Fellowship Award Winner 2012/2013, 2013/2014

2012 Miss Kentucky Scholarship Organization Volunteer of the Year Award

KYANNA Black Nurses Association Distinguished Nurse Award 2010

Cum Laude Graduate, Berea College

Dean's List

Captain, Women's Basketball Team, Berea College (4 years)

Miss University of Louisville 2008

Spokesperson STOP AIDS, Cincinnati, Ohio, 2010

\section{Committees and Services}

Community Service

Berea College Young Alumni Advisory Council

Board Member, Kentucky Workforce Innovation Board (Appointed by

Governor Steve Beshear)

Volunteer, The Healing Place

Board Member, Miss Kentucky Scholarship Organization

Executive Director, Miss Kentucky’s Outstanding Teen Scholarship

Organization

Motivational Speaker to various community organizations

Founder, Project L.O.U.I.E.

2015 Bingham Fellow

\section{Teaching}

a. Undergraduate

University of Louisville

Guest Lecturer for Maternal/Newborn Course (NURS 461)

-Contraception Content

- 90 students taught, 2 lectures

Maternal/Newborn Clinical Instructor (NURS 461)

-30 students throughout spring semester

b. Graduate

University of Louisville

Guest Lecturer for Women's Health Nurse Practitioner Course (WHNP I)

- LGBTQ Content

- 5 students taught

University of Louisville

Clinical Evaluator

Women's Health Nurse Practitioner Students

-Midterm and Final evaluations at clinical sites 


\section{Abstracts and Presentations}

Workshops:

Hines-Martin, V., Edward, J. and Miller, A.

"Engaged Research with Non-Traditional Populations"

Southern Nursing Research Society Conference- Pre-Conference Workshop

Competitively Selected, Spring 2015

Podium Presentations:

"Positive Deviants in Family Planning: A Qualitative Study"

Southern Nursing Research Society Conference

Competitively Selected; Spring 2016

Poster Presentations:

"Contraceptive Self-Efficacy in Adolescent Females: A Pilot Study"

Southern Nursing Research Society Conference

Competitively Selected; Spring 2014

"Contraceptive Self-Efficacy in Adolescent Females: A Pilot Study"

Research Louisville

Competitively Selected; Fall 2013

"Interactive Case Studies in Reproductive Health Problems"

University of Southern Indiana Nursing and Health Professions Educator

Conference

Competitively Selected; Fall 2012

Publications:

Miller, A. (2014). The forgotten victims: The women of Tuskegee. The Journal of African American Studies, 33(2), 1-8. 